Maintenance Optimization and Inspection Planning of Wind Energy Assets: Models, Methods and Strategies

Mahmood Shafiee, John Dalsgaard Sørensen

PII: S0951-8320(16)30789-X

DOI: 10.1016/j.ress.2017.10.025

Reference: RESS 5993

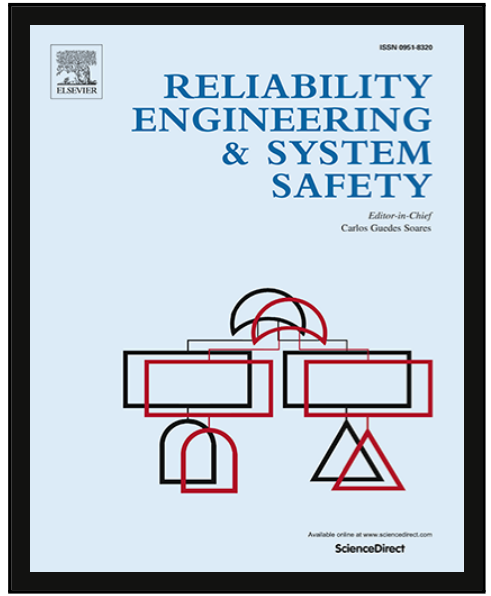

To appear in:

Reliability Engineering and System Safety

Received date:

13 November 2016

Revised date:

21 May 2017

Accepted date:

27 October 2017

Please cite this article as: Mahmood Shafiee , John Dalsgaard Sørensen , Maintenance Optimization and Inspection Planning of Wind Energy Assets: Models, Methods and Strategies, Reliability Engineering and System Safety (2017), doi: 10.1016/j.ress.2017.10.025

This is a PDF file of an unedited manuscript that has been accepted for publication. As a service to our customers we are providing this early version of the manuscript. The manuscript will undergo copyediting, typesetting, and review of the resulting proof before it is published in its final form. Please note that during the production process errors may be discovered which could affect the content, and all legal disclaimers that apply to the journal pertain. 


\section{Highlights}

- A classification framework for the study of maintenance policy optimization and inspection planning in wind energy industry;

- To identify models, methods and strategies used to optimize maintenance decisions and inspection procedures for various wind energy assets (turbines, foundations, cables, electrical substations, etc.);

- A systematic review of the literature over the past two decades (1997-2016);

- Identify critical observations on each category of classification;

- Suggest directions of potential interest to operational researchers. 


\title{
Maintenance Optimization and Inspection Planning of Wind Energy Assets: Models, Methods and Strategies
}

\author{
Mahmood Shafiee $^{{ }^{\dagger}}$, John Dalsgaard Sørensen ${ }^{\mathrm{b}}$ \\ ${ }^{a}$ Centre of Offshore Renewable Energy Engineering, Cranfield University, Bedfordshire MK43 \\ OAL, United Kingdom \\ ${ }^{\mathrm{b}}$ Department of Civil Engineering, Aalborg University, Sofiendalsvej 9-11, 9200 Aalborg, \\ Denmark \\ Abstract
}

\begin{abstract}
Designing cost-effective inspection and maintenance programmes for wind energy farms is a complex task involving a high degree of uncertainty due to diversity of assets and their corresponding failure modes, weather-dependent transport conditions, unpredictable spare parts demand, insufficient space or poor accessibility for maintenance and repair, limited availability of resources in terms of equipment and skilled manpower, etc. In recent years, maintenance optimization has attracted the attention of many researchers and practitioners from various sectors of the wind energy industry, including manufacturers, component suppliers, maintenance contractors and others. In this paper, we propose a conceptual classification framework for the available literature on maintenance policy optimization and inspection planning of wind energy systems and structures (turbines, foundations, power cables and electrical substations). The developed framework addresses a wide range of theoretical and practical issues, including the models, methods, and the strategies employed to optimise maintenance decisions and inspection procedures in wind farms. The literature published to date on the subject of this article is critically reviewed and several research gaps are identified. Moreover, the available studies are systematically classified using different criteria and some research directions of potential interest to operational researchers are highlighted.
\end{abstract}

\section{Keywords}

Wind energy; Asset management; Inspection; Maintenance; Repair; Optimization; Reliability.

\footnotetext{
${ }^{\dagger}$ Corresponding author. Tel.: +44 1234750111.

Email addresses: m.shafiee@cranfield.ac.uk (M. Shafiee), jds@civil.aau.dk (J.D. Sørensen).
} 


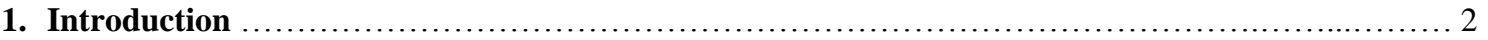

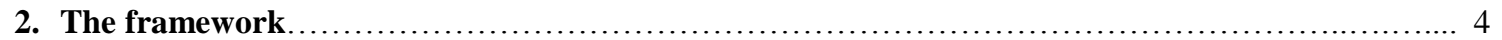

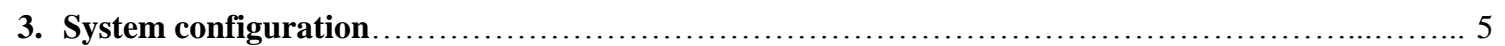

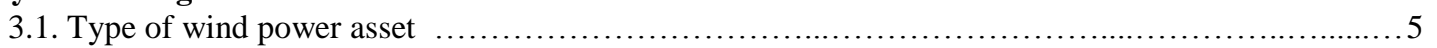

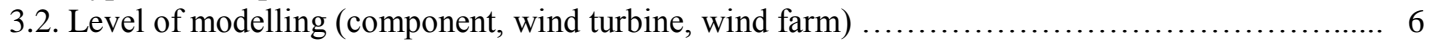

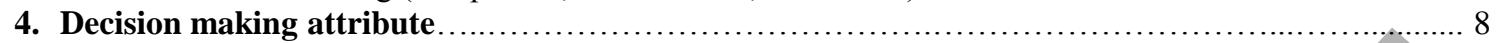

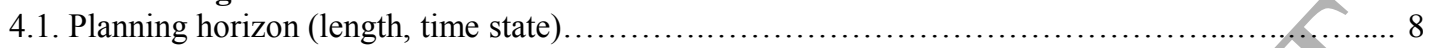

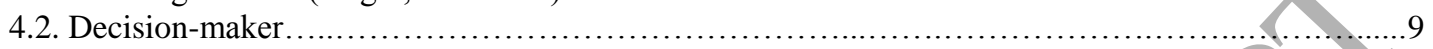

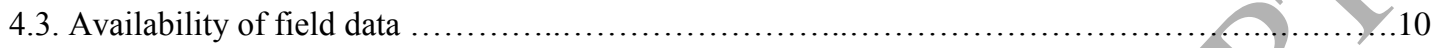

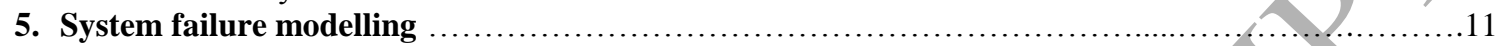

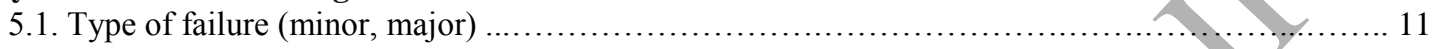

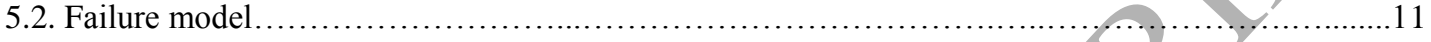

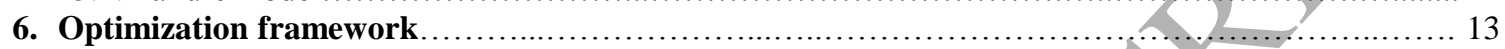

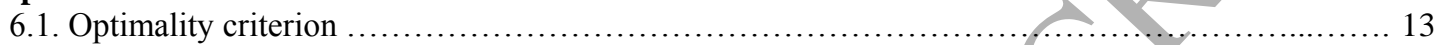

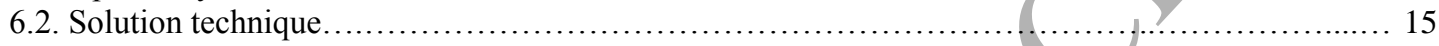

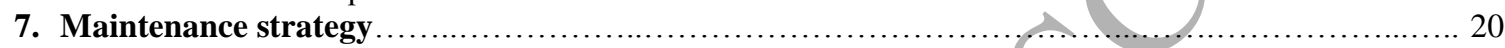

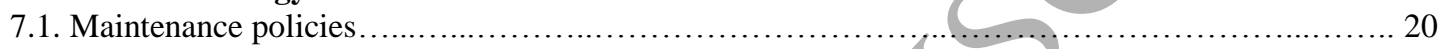

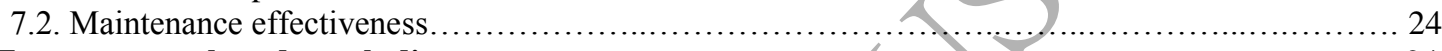

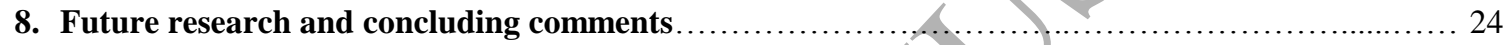

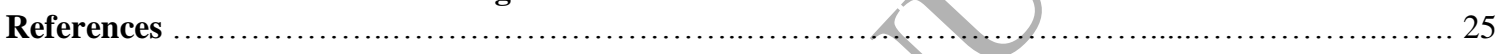

\section{Introduction}

Global warming, binding targets on greenhouse gas emissions and high costs of fossil fuels have created an urgent need to shift from traditional sources of energy to renewable ones. This shift to renewable sources of energy has accelerated at a very rapid pace after the Fukushima Daiichi nuclear disaster in Japan in March 2011 [1]. Wind power is recognized as one of the most attractive renewable energy sources which supplies an affordable, inexhaustible and clean energy to the economy. Over the last decade, wind power generation has experienced an extensive and worldwide growth. For instance, the cumulative installed capacity of wind power in the European Union (EU) has increased from 47.8 gigawatts (GW) in the year 2006 to $153.7 \mathrm{GW}$ in the end of 2016, representing an annual growth of over $12 \%$ (see Figure 1). The share of wind power in EU's electricity supply was $10.4 \%$ in 2016, while it is forecasted to reach up to $20 \%$ by 2030 [2].

\section{"Fig. (No. 1)"}

Figure 1. Cumulative installed wind power capacity in the EU during 2006-2016 [2].

Along with the growth of the market for wind energy, a great deal of attention has been focused recently on minimising operation and maintenance (O\&M) costs of the installed wind turbines while ensuring high levels of reliability and safety. Currently, the O\&M costs (including all expenditures associated with planned and unplanned repair tasks) constitute a substantial part of the total life-cycle cost of wind turbines. According to existing statistics, the O\&M costs of a wind project with twenty-year life span account for about 15-30\% of the overall energy generation cost or equivalently $75-90 \%$ of the initial investment [3]. 
Wind farm owners and operators have been under increasing pressure recently to reduce O\&M costs. It will become even more critical in the near future as the wind turbine capacity ratings continue to rise and the wind farm siting moves towards offshore locations. O\&M cost reduction can mainly be achieved by developing and implementing 'costeffective' and 'well-planned' inspection and maintenance programmes for wind farms. Nowadays, the planned maintenance tasks are undertaken during periods when demand for electricity is low (i.e., low-load seasons) or while service vessels (ships, helicopters, lifting cranes) are available to provide logistics support. It has been reported in some large wind projects (e.g. Opti-OWECS ${ }^{1}$ ) that a significant portion of annual budget is wasted as the result of unnecessary or improperly carried out maintenance activities. A cost-effective maintenance strategy aims to reduce the frequency of service interruptions as well as avoiding undesirable consequences of such interruptions. The maintenance tasks affect system reliability in a way that if too little maintenance is performed, it may result in an excessive number of costly failures and high production losses. However, if maintenance activities are performed too often, the reliability will improve but the cost of maintenance may potentially increase to unsatisfactory levels [4]. For this reason, finding "cost-optimal" solutions for inspection and maintenance operations at wind farms requires an appropriate balance between reliability targets and the cost to achieve those targets.

Maintenance optimization is defined as a method aimed at determining the most effective and efficient maintenance plan (i.e., inspection time and frequency, work preparation, required maintenance resources) so that the best possible balance between direct maintenance costs (e.g. manpower cost, logistics and transportation costs) and the consequences of not performing maintenance (e.g. loss of power production and assets) is achieved. Designing an optimal maintenance plan during the relatively long life span of wind farms is a complex task involving a high degree of uncertainty due to diversity of assets and their corresponding failure modes, existence of various dependencies among components of assets, weather-dependent transport conditions, unpredictable spare parts demand, insufficient space for replacement or poor accessibility for maintenance and repair, limited resources in terms of supply vessels, specialized equipment, trained workforce, etc. Thus, it is crucial to develop effective models and efficient techniques capable of incorporating all the factors and uncertainties associated with wind farm inspection and maintenance.

In recent years, many researchers and practitioners have shown their interest in the study of maintenance policy optimization and inspection planning for wind energy systems [5-7]. However, the literature on classification of the associated models, methods and strategies has been very limited and there remains a big gap between academic research and application in practice. In this paper, we propose a conceptual classification framework for optimizing maintenance decisions and inspection procedures in the wind energy industry. The academic studies as well as industrial applications reported on the topic are identified, reviewed and classified systematically. The relevant issues in each category are discussed in details and several gaps are identified subsequently. Some research directions of

\footnotetext{
${ }^{1}$ Structural and Economic Optimization of Bottom-Mounted Offshore Wind Energy Converters
} 
potential interest to operational researchers are also highlighted. To the best of the authors' knowledge, this paper is the first study to review a large number of research works and industrial case studies carried out over the past two decades (1997-2016) on the inspection planning and maintenance optimization of wind energy assets, including: wind turbines, support foundations, power cables and electrical substations. The findings of this research can provide valuable insights to researchers about the procedures and methodologies used for inspection and maintenance decision-making of wind energy farms.

The rest of this paper is organized as follows. First, the classification framework applied to this study is proposed; then, for each category of classification the available literature is reviewed and the relevant issues are discussed; and last, we outline our conclusions and give a brief discussion of future research topics.

\section{The framework}

In this section, we introduce a classification framework to identify various theoretical and practical issues including the models, methods, and the strategies employed by wind farm operators for inspection planning and maintenance optimization of wind turbine components and structures. According to the framework shown in Figure 2, the available studies on the subject can be categorized using the following criteria:

(a) System configuration (type of wind power asset and the level of system modeling);

(b) Decision-making attribute (planning horizon, the decision-maker and the availability of field data);

(c) System failure modelling (type of failure and the failure modeling approach);

(d) Optimization model (optimality criterion and the solution technique);

(e) Maintenance strategy (maintenance policy and the repair effectiveness).

\section{"Fig. (No. 2)"}

\section{Figure 2. The classification framework proposed for the study}

The above five classification criteria are then decomposed into various categories. For the purpose of this categorization, the academic studies and industrial best practices reported to date in the literature were identified, reviewed, and analyzed. The selected studies include contributions from both scholars and practitioners in scientific journals, master's and doctoral theses, textbooks and case study reports. Conference papers and unpublished dissertations were excluded from this study because of their wide variety of contexts and the difficulties in obtaining manuscripts, particularly those dating back more than a decade. As the literature was scattered across numerous journals and government reports, the following online sources were searched by text mining techniques and the use of citation indexes: 
ABI/INFORM Global - ProQuest; Academic Search Premier; Blackwell Synergy; Business Source Premier - EBSCOhost; Compendex (Engineering Village) - Elsevier Engineering Information; Emerald Fulltext; IEEE Transaction; ISI Web of Knowledge; NTIS - Ovid (SilverPlatter); Scopus - Elsevier; Springer Link; and Wiley InterScience.

For the searching criteria, two primary keywords of "wind energy" and "maintenance" were first used. Next, other search terms such as "wind turbine", "wind farm", "inspection", "model", "method", "technique", etc. were combined with the primary keywords for wider search results. Then, the full text of each work was carefully reviewed to eliminate those that were not related to the field of "optimization" or "scheduling". Finally, two hundred and forty-six publications including one hundred and seventy-nine journal articles [8-186], thirty-seven master and doctoral dissertations [187-223], twelve textbooks [224-235], and eighteen industrial reports [236-253] were selected for their relevance to the topic. Figure 3 represents a bar chart of number of publications concerning maintenance policy optimization and inspection planning of wind turbine systems in five-year periods, from 1997 to 2001, 2002 to 2006, 2007 to 2011, and 2012 to 2016.

"Fig. (No. 3)"

Figure 3. Distribution of the studies by year of publication (1997-2016).

As can be seen, over $72 \%$ of the publications have appeared during last five years which indicates the increasing importance of the maintenance optimization in wind energy industry. In following five sections, a detailed distribution of the publications classified according to the proposed framework is given. Since a large number of studies have been published in each category, only a brief description of some featured publications is provided.

\section{System configuration}

\subsection{Type of wind power asset}

A wind farm system includes different groups of mechanical, electrical and structural assets including wind turbines, foundations (e.g. gravity based, suction-bucket and pile), support structures (e.g. monopile, tripod and jacket), transition pieces, connection cables, electrical substations, etc. Wind turbines convert energy from the wind into electrical energy. The/foundations provide support for the wind turbine structures that are installed above sea level. Support structures are used to connect the transition piece or tower to the foundation. Electrical substations connect the wind turbines to the national electricity grid. Connection cables transmit the power from the individual turbines to the substation.

In general, there are two alternatives of wind power generation, namely, onshore and offshore. The technologies involved in both the onshore and offshore wind turbines are almost similar. One of the main differences between onshore and offshore wind turbine designs is their foundation structures. Onshore wind turbines are fixed to the ground with a 
concrete foundation, whereas offshore wind turbines have their foundations on the sea bed (fixed-bottom) or in the water (floating). In recent years, a large number of wind farms have been built in offshore locations due to high wind resources and the availability of large areas for installation. According to existing statistics, the O\&M cost of offshore wind turbines accounts for larger portion of the cost of power generation than that of onshore wind turbines. The O\&M costs for onshore wind farms comprise 5 to $10 \%$ of the cost of energy (COE) while it is estimated to be between 20 to $35 \%$ in offshore wind projects. This big difference might be due to negative impacts of offshore environment on performance of the wind turbines. Offshore wind turbines have to withstand harsh maritime conditions and their accessibility for maintenance and repair is generally poor in periods of strong wind and high waves. Moreover, the maintenance expenditures will be much higher for wind projects constructed in ultra deep waters at long distances from the shore. Therefore, in order to make offshore wind power generation more cost-competitive with onshore production as well as with the other sources of offshore renewable energy (wave and tidal), the associated O\&M costs must be significantly reduced.

While building an optimal maintenance and replacement model for wind farms, the following key factors must be taken into consideration:

- size and orientation (micro-sitting) of the wind farm;

- power rating, and capacity factor of the wind turbines;

- reliability of the wind turbines;

- accessibility and availability of support vessels and transportation means;

- distance to shore and water depth; and

- meteorological surrounding conditions (wind, waves, and visibility).

A brief review of the literature shows that a lot of research has been done on optimization of the maintenance decisions for onshore wind farms (see, e.g. [23, 72, 189]). But, the existing models need to be extended to address the unique characteristics of the offshore wind farms. Utne [35] proposed a framework to make the maintenance activities more efficient for offshore wind turbines located in remote deep water areas. The two $\mathrm{PhD}$ dissertations of Karyotakis [203] and Sinha [223] studied the optimization of maintenance strategies for offshore wind farms. Tavner [226] in his recent book addressed the reliability, availability, and maintainability (RAM) challenges of offshore wind farms. The readers can also refer to $[11,29,44,53,55,56,61,70,89,104,106,111,123,128,129,133,136,144$, $145,146,147,157,161,163,164,167,168,171,179,180,202-205,214,219,222,230$, 248, 251 for further reading on optimal inspection and maintenance of the offshore wind turbines. Also, the studies [24, 60, 199, 206] and [247] are concerned with the inspection planning of foundation structures, power cables and substations, respectively.

Sinee the maintenance optimization process is considered as a typical complex decision-making problem, the need for software-based solutions has also greatly increased. In this line, Sinha et al. [90] recently developed an offshore-centric software package for optimization of the maintenance decisions in wind farms. 


\subsection{Level of system modelling (component, wind turbine, wind farm)}

The optimization of maintenance decisions in the wind energy sector can be done regarding a hierarchical scheme including the three levels of component, wind turbine, and wind farm (grid). These modelling levels are described as following:

\section{- Component level}

At the component-level analysis, an optimum maintenance decision model is developed for individual critical components of system, such as gearbox, rotor blade, and generator. In this analysis approach, each component is considered as an isolated unit and the possible dependency among components is neglected. Over the past two decades, a vast majority of the literature focuses on optimization of the maintenance for individual components (or being possibly assimilated to single-unit systems). Besnard and Bertling [30] presented an approach for optimization of the inspection interval and condition monitoring strategies for a blade whose deterioration is classified according to the severity of damages. In another work, Deng et al. [50] proposed a maintenance optimization model to determine the inspection interval for wind turbine gearbox such that the mean profit per unit time was maximized. Igba et al. [154] developed an approach for evaluating the effect of preventive maintenance (PM) interval on reliability and O\&M costs of wind turbine gearbox. The readers can also refer to these references for further: $[9,10,46,48,64,68,89$, $94,97,107,110,116,134,152,159,164,165,174,228,250]$.

\section{- Wind turbine level}

Even though the single-unit maintenance models are generally considered as a basis for building more complex models, they cannot be applied to real-world systems. The component-level models assume that the components are independent, and thus are replaced individually (one-by-one). However, a single component failure in the system may affect the performance of other components which are structurally dependent, and it may cause a multiple component replacement. The related factor leading to multiple item replacements is called common cause failure (CCF) (for more see [198]).

It is very often observed that some critical components in wind turbine are stochastically dependent on each other. Stochastic dependence implies that failure or degradation of one component can influence the lifetime distribution of other components (e.g. construction error). Neglecting component dependencies while optimizing the maintenance and repair decisions may lead to sub-optimal or even wrong solution to the problem and thereby increased cost of maintenance and system downtime. When considering the key components, a wind turbine can be treated as a series reliability system. In these types of systems, the components are connected together in series and any failure in one of the components causes the failure of entire system. A repair policy for a series wind turbine system was studied in $[15,16,21]$. For more references on system-level maintenance optimization approach, the readers can refer to $[20,22,27,29,31,32,36,38$, $53,55,56,59,62,71,73,78,80,82,99,178,113,118,121,131,132,148,150,158,161$, $162,163,170,182,185,190,192,197,208,218,220,221,225]$. 


\section{- Wind farm ( grid) level}

An increasing interest has been recently devoted to the development and optimization of maintenance strategies for large-scale wind farms which consist of hundreds of wind turbines. The development of maintenance optimization models for a large-scale wind farm is much more complex than that for an individual wind turbine. The maintenance decisions for a group of wind turbines in a wind farm must be made in conjunction with what happens to the other wind turbines. Generally, two kinds of dependencies are considered between wind turbines in a farm: failure dependence (or correlation) and economic dependence. Failure dependence means that once a wind turbine is shut down for maintenance, all the posterior wind turbines in farm may also have to be stopped. Economic dependence is, when a support vessel is hired to carry out the repair actions on a failed item, it might be economical to take this opportunity and perform some preventive maintenance (PM) tasks on non-failed (but soon-to-fail) wind turbines.

Failure and economic dependencies among the wind turbines have received very limited attention to date. Tian et al. [45] identified two types of dependencies among wind turbines in a wind farm. The first type of dependence is to share maintenance set-up costs between different wind turbines, and the second type is the dependence exists between wind turbines with high risk of failure. Pérez et al. [160] proposed algorithms for scheduling maintenance processes in wind farms with multiple turbines comprising multiple components, including the gearbox, power generator, blades and control system. Amayri [200] investigated the optimal condition-based maintenance policy for a wind farm consisting of various types of wind turbines with different lead times. For more references on this category, the readers can refer to $[11-13,26,34,37,41,51,61,65,66,69,70,72$, 77, 79, 83, 86, 98, 101, 103, 106, 111, 114, 128, 129, 137-139, 144-147, 149, 153, 157, $167,168,172,173,175,179,184,201,205,219,239]$.

\section{Decision-making attributes}

\subsection{Planning horizon (length, time-state)}

The planning time horizon in maintenance optimization can be studied from two different views: the length of time horizon, and the type of time states. These aspects are described as following:

\section{- Length of time horizon (infinitelfinite/random)}

The length of planning period for optimal maintenance decision-making problem is normally defined as either infinite, finite, or random. Infinite time horizon models deal with decisions that have long-lasting effect (e.g. for twenty-five years) on system O\&M. This kind of models often uses the net present value (NPV) technique to recalculate all costs of maintenance to the present value (for more see $[81,136,158,196])$. In finite-time planning models, the horizon can represent, for example, the period of a repair contract set by the manufacturer or an independent service provider (see, e.g. [155]). The random time horizon models assume that the system terminates at a random point of time, e.g. the system is 
replaced by a new one either at random failures or at a given operational age, whichever comes first (see, e.g., $[162,163]$ ).

\section{- Time states (discrete, continuous)}

Maintenance scheduling models, depending on the considered time state, can be divided into two classes: discrete and continuous. Discrete-time models assume that the maintenance tasks are scheduled at discrete points in time, whereas continuous-time models relax this restriction. In practice, the duration of maintenance activities and transportation times are expressed as integer multiples of time periods whose length may vary from one hour to one week. Besnard et al. [194] proposed an opportunistic maintenance optimization model using a discrete-time scale representation for offshore wind farms. The scheduling horizon was divided into a series of short and long time intervals, depending on the availability of forecasting information. Kovács et al. [41] developed an optimal wind farm maintenance schedule over a short-term rolling horizon (e.g. three to seven days). In a rolling horizon, the maintenance schedule is updated frequently to react to changes in meteorological surrounding conditions (wind, waves, and visibility). For more references on discrete-time maintenance models, see [118].

\subsection{Decision-maker}

The maintenance optimization problem in the wind energy industry can be considered from three competing points of view-wind turbine manufacturer, wind farm owner and operators, and the independent service providers.

\section{- Wind turbine manufacturer}

Nowadays, wind turbines are sold with a 2- to 5-year full-service contract from the manufacturers. Under this contractual agreement, the manufacturer is obliged to rectify any system failures caused by design, manufacturing, and quality assurance problems as well as provide technicians over a specified period of time. Offering a full-service contract for wind turbines may result in significant servicing costs to the manufacturer. This servicing cost typically involves the costs of repairing failures through corrective maintenance (CM) during the early years of operation, called 'infant mortality' [34]. Therefore, finding an effective way to reduce the servicing costs over this period has become an issue of great importance to wind turbine manufacturers.

One possible way to reduce servicing costs is to make sound decisions on design of wind turbines which is known as 'design for reliability (DFR)' in the context. The main purpose of implementing DFR techniques in the wind turbine manufacturing industry is to minimise the number of failures experienced over the lifetime, which results in enormous savings in maintenance and energy production costs. The DFR methodology has received an increasing importance in recent years, especially for some critical components like rotor blades, gearbox, and generator (see [8-10, 17, 187]). The readers can also refer to [243] as an industrial report on optimising the design processes for wind turbines in order to reduce the associated O\&M costs within the RELIAWIND project.

\section{- Wind farm owner and operators}


The system owners' point of view on maintenance optimization might be totally different from wind turbine manufacturers'. After the expiration of service contract, the maintenance expenditures are borne completely by the wind farm owners until wind turbines reach the end of their service life. The O\&M costs of a wind turbine over its operational life can be controlled through conducting preventive maintenance actions. To this aim, scheduled PM actions are carried out during the constant failure rate period (between fifth year and fifteenth year of operation) to prolong the useful lifetime as well as over the wear-out period (usually after the fifteenth year of operation) to reduce the degradation rate. Ortegon et al. [113] presented a system dynamics (SD) approach to model the interactions between maintenance, reliability, and technological obsolescence on the remanufacturing of a wind turbine at the end-of-use (EOU). The study suggested that regular preventive maintenance (PM) avoid/slow functional obsolescence, and as a result, the remanufacturing cost is reduced. Recently, a number of wind turbine manufacturers (see [246, 252]) launched a program to extend the twenty-year lifetimes of the $850 \mathrm{~kW}$ wind turbines to an expected life of thirty years or even more.

\section{- Independent service providers}

Currently, many of the wind farm owners employ an independent service provider to carry out the maintenance tasks under properly drafted contracts. Maintenance contracts usually specify a target for the 'availability' of wind turbines (i.e., the proportion of time that system is functional and working). Hence, the service provider-sometimes, the service department of the manufacturer-aims to maximize the availability whilst minimizing the production losses. Jin et al. [155] proposed a game-theoretical optimization model to minimize the O\&M costs of wind turbines under a performance-based contract (PBC). According to this type of agreement, the wind farm owner defines an availability target and signs a contract with a service provider. Then, the service provider will be committed to reliable performance of the wind turbines.

\subsection{Availability of field data}

The data availability is seen as the biggest challenge in RAM studies of the wind energy industry [39, 242, 250]. Effective management of maintenance activities in a wind farm requires a database of failure data to model the system failures as well as some supplementary data to evaluate the different maintenance strategies. Failure data (e.g. times to failure) are collected and stored during the operation as well as servicing of the wind turbines. They can usually be collected from Supervisory Control And Data Acquisition (SCADA) or some other sources like WMEP in Germany (www.wmep.org), WindStats in Denmark (www.windustry.org/resources/wind-stats-newsletter), VTT in Finland (http://www.vtt.fi), or Elforsk in Sweden (http://www.elforsk.se). The failure databases usually contain valuable information about the performance and failure history of wind turbines which can be effectively utilized to detect the potential future failures. Supplementary data (e.g. cost parameters, production levels) are collected from other internal or external sources. 
Currently, much of the data available in wind farm databases suffers from inaccuracy, inconsistency, and incompleteness. However, a brief review of the literature shows that very few research has been conducted on the optimization of maintenance decisions under data limitations. Coolen et al. [22] applied non-homogeneous Poisson process (NHPP) models, in particular the power law process, to derive the reliability of wind turbines and some critical subsystems from grouped data with little information on individual turbines or maintenance activities. Guo et al. [28] proposed a three-parameter Weibull failure rate function for wind turbines when the field failure data is incomplete. Nguyen et al. [84] and Nguyen [217] presented a data integration framework for optimization of the O\&M decisions within offshore wind farms.

\section{System failure modelling}

\subsection{Type of failure (minor, major)}

It is important to distinguish between the different types of failures that may occur in a wind farm because the required resources to perform the associated repair tasks will be different. Basically, the wind turbine failures can be classified into two types of minor and major (catastrophic) [164]. Minor failures (e.g. microscopic cracks) are often detected remotely and are rectified through a minor inspection, whereas major failures (e.g. a metrelong fracture) can only be removed by a major repair or replacement. The resources required to carry out maintenance tasks will vary according to whether the action is a major overhaul or just a minor repair. For instance, a minor repair task on the yaw brake pads can be executed by a team of two technicians and it normally takes about 30 minutes. In contrast, a major repair task on a rotor blade (e.g. de-icing) needs two teams of two technicians and it takes almost four hours. Moreover, in order to conduct a minor inspection the maintenance crew can be transported by either a workboat or a helicopter, while for a major repair they must be sent only by a workboat.

\subsection{Failure model}

The method used for modelling of the failure process of components is a very important input for the maintenance optimization analysts. These methods can be classified into different types as follows:

- Black-box/Grey-box/White-box

In the black-box modeling approach, a wind turbine system is considered as a single module and)its reliability is estimated using the available failure data (e.g. the recorded times-to-failure). Since this model does not consider the relationships between components, it is often used for optimization of the maintenance decisions at component level. In the grey-box modeling approach, the degradation process underlying a failure is modeled. This implies that the deterioration can be observed (classified or measured) directly or indirectly by relevant deterioration indicators. Besnard [210] used a grey-box approach for deterioration and maintenance modeling of wind turbines. The approach consists of a life cycle cost (LCC) model for the whole lifetime of wind turbines which takes into account 
the cost consequences of random failures (e.g. lightning strike). In the white-box modeling approach, the system is considered as a collection of components, subsystems and assemblies arranged together in a specific structure to achieve the desired functionality. Thus, the technique can be useful in deriving the reliability of a system based on the reliability of its constituent components using classical reliability theory. Andrawus et al. [15] applied the white-box approach to assess the failure characteristics of a horizontal axis wind turbine system. An optimal maintenance strategy was also proposed to minimize the total LCC of wind farm.

- Delay-time model

The concept of delay-time model is very similar to the Potential-to-Functional Failure (P-F) curve in reliability-centred maintenance (RCM). The P-F curve illustrates the point where a failure starts occurring but not detectable $(\mathrm{P})$, and the point where the system fails (i.e., the functional failure point) $(\mathrm{F})$. The time taken from potential failure to decay into functional failure is called 'P-F interval'. In delay-time models, the criterion for declaring points $\mathrm{P}$ and $\mathrm{F}$ is very important. In the RCM analysis, the point $\mathrm{P}$ is determined on the basis of experts' judgments. When the experts agree that a potential failure is present, the maintenance technicians immediately decides on replacing the component. If this is not the case, then the periodic inspections have to be conducted at intervals of length $x$ aiming to estimate the severity level of failures ( $x$ is shorter than the average PF interval). The delaytime model has been well addressed in reliability analysis of wind turbine systems (see [16]). This model can be used for deriving the reliability of wind turbine structural components by the means of structural reliability theory, limit state modeling, first-order reliability method (FORM) or second-order reliability method (SORM). In a study carried out by Andrawus et al. [21], a delay time maintenance model was proposed to determine an optimum inspection interval for major components of wind turbines.

\section{- Multi-state model}

Most of the existing failure models assume that a system consists of binary-state components whose behavior is described only by two possible states: perfect functionality and complete failure. However, many real-world systems are composed of multi-state components having different performance levels and several failure modes with various effects on the entire system's performance. Such systems are called multi-state systems. Multi-state reliability methods are found to be very useful for modelling the failures and repair activities of wind turbines as they can include the dynamic characteristics of the system. For instance, since wind speed does not maintain a specified stable level, using a multi-state model would result in a more accurate estimation of the system's reliability.

\section{- Degradation model}

Many of the wind turbine components such as gearbox and generator or wind farm structures such as foundations are exposed to degradation processes such as fatigue cracking, corrosion, corrosion fatigue, scour, etc. Wind asset degradation is a very complex process as it depends on numerous physical and environmental factors (such as material, 
stress loads, temperature) and usually manifests itself in different forms of wear, fatigue, and crack generation. The prediction of degradation level (e.g. crack size) is very important for reliability analysis as well as scheduling of inspection and maintenance tasks for wind turbines. The degradation behavior of a component is usually modeled by a stochastic process, namely $\{X(t), t \geq 0: X(0)=0\}$ which represents the level of deterioration (e.g. accumulated wear) at time $t$. If no maintenance action is taken, $X(t)$ will be continuous-time and monotonically increasing function.

The degradation process of wind turbines has been extensively analyzed in the last decade and some models have been developed to assess the risks associated with degradation failures (for more see [227]). Among the stochastic processes considered in this context, the gamma process has been satisfactorily fitted to data of different degradation phenomena in wind turbines. Shafiee and Finkelstein [162] applied the gamma process to degradation analysis and maintenance planning of a group of wind turbine bearings. Le and Andrews [170] presented a reliability assessment model for offshore wind turbines subject to degradation in order to plan inspection and maintenance processes. The model captured the stochastic nature of the dynamic processes through the use of appropriate statistical distributions.

\section{- Shock models}

It is widely reported that the wind turbine failures are not solely caused by components' degradation. Besides degradation failures, wind turbines may also be subject to external (environmental) shocks such as destructive waves and icing damages. According to IEC 61400-3 (www.iec.ch), the external conditions of a wind farm (e.g. wind speed, wind direction, turbulence intensity) should be continually monitored and the essential design requirements must be specified to ensure the engineering integrity of wind turbines. The existing shock/models are concerned with a multi-unit wind turbine system whose components are subject to different external shocks at random times and are damaged by a shock impact. In the literature, there are four groups of shock models: (i) extreme shock models in which a failure occurs when the magnitude of a shock exceeds a pre-specified threshold, (ii) cumulative shock models in which a failure occurs when the cumulative damage from shocks exceeds a critical value, (iii) run shock models in which a failure occurs when there is a run of $k$ shocks exceeding a critical magnitude, and (iv) $\delta$ shock models in which a failure occurs when the time lag between two successive shocks is shorter than a threshold $\delta$. The readers can refer to these references for further: $[164,186]$.

\section{Optimization framework}

\subsection{Optimality criterion}

The objectives taken into account in the literature for optimization of the maintenance decisions are divided into the following three general categories:

\section{- Minimum cost}


The criterion of minimum 'long-run average cost' is widely used in the maintenance optimization area. Let $D(t)$ denote the expected cost of operating a system over the time interval $(0, t)$. Let $L_{i}$ be the length of the $i^{\text {th }}$ replacement cycle and $O C_{i}$ be the operational cost over the cycle. A replacement cycle is defined as a time interval between two consecutive replacements. Then, from the renewal reward theorem, the long-run average cost is equal to the expected operational cost over a cycle divided by the expected length of the cycle, i.e.,

$$
\text { Long-run average cost }=\frac{\text { Expected cost incured in a replacement cycle }}{\text { Expected length of a replacement cycle }}=\lim _{t \rightarrow \infty} \frac{D(t)}{t}=\frac{E\left[O C_{i}\right]}{E\left[L_{i}\right]} .
$$

For each replacement cycle, five cost drivers are often considered in model formulation, namely, replacement cost (of a failed item by a new one); logistics costs (of equipping the maintenance crew, hiring the service vessels, and ordering the spare parts); transportation cost (for sending the maintenance crew to wind farm); manpower cost (for the inspections and CM tasks on failed components); and production loss cost (due to wind farm breakdown). All the above costs are included in life support cost (LSC) which usually accounts for a significant part of the wind turbine lifecycle cost and should be minimized. To this aim, various routine inspections are carried out to improve the operating conditions of wind turbines as well as reducing cost of energy produced by wind farms. The cost of energy (COE) produced from wind farms is given by [254]:

$$
C O E=\frac{I C \times F C R+A O M}{A E P},
$$

where $I C(£)$ is the initial capital cost of the wind farm; FCR (\%/year) is the fixed charge rate; $A O M$ (£/year) is the annual O\&M cost; and $A E P(\mathrm{kWh} /$ year) is the annual energy production. For further reading on maintenance optimization models with minimum cost criterion, the readers can refer to $[32,44,45,51,55,68-70,81,103,162-164,185,194$, $197,200,208,210,225,238]$.

\section{- Minimum production loss (maximum power output)}

There are seyeral categories of energy production losses in a wind power plant, including wake losses, availability losses, turbine performance losses, electrical losses, environmental losses, etc. Wake losses are one of the most important factors leading not only to reduction of power output, but also an increase of structural loading on wind turbines. The wake losses are often caused by the momentum deficit and increased level of turbulence created by wind turbines in the wind farm. To date, the effects of energy production losses due to wake effects have been seldom considered for the scheduling of wind farm maintenance (e.g. see [97]). Availability losses are another type of production loss in wind farms. When an unexpected failure occurs in a wind turbine, the whole system stops operating until the required repair is completed. An unexpected failure results in considerable production losses in wind farms. Besides random failures, power loss may be caused by scheduled PM tasks where the wind turbines are normally shut down during the 
maintenance actions. The optimization of maintenance strategies with the aim of minimizing total production losses (or maximizing total power output) has been of considerable interest to wind farm operators. Kovács et al. [41] developed a mixed-integer programming model to optimize the maintenance schedule of an onshore wind farm. In the proposed model, the objective function includes both production losses due to random failures and PM actions, that is,

$$
\min \sum_{j=1}^{J} \sum_{t=1}^{T} z_{j, t}+\sum_{i=1}^{N} \delta_{i} y_{i}
$$

where $z_{j, t}(\geq 0)$ denotes the production loss of turbine $j$ over period $t$; the indices $J$ and $T$ represent respectively, the number of wind turbines in wind farm and the number of time periods in planning horizon. The binary variable $y_{i}$ indicates whether PM task $i$ (among $N$ tasks) is postponed or not. This means that it may be worth postponing PM tasks, e.g. from a period with high winds to a later period with low winds, even if all resources are available. If the PM task is performed exactly after the failure, then $y_{i}=0$; otherwise if it is postponed, $y_{i}=1$ and a penalty cost $\delta_{i}(\geq 0)$ incurs to the decision-maker. The readers can refer to $[12,57,95,181]$ for further.

- Maximum availability/reliability

The analysis of failure data collected from various databases shows that the availability of existing wind farms is less than the target levels [95-99]\% (for more see [18, 19, 42]). Generally, the following ways can be considered to achieve a higher level of availability in wind farms:

- Using faster transportation means;

- Coordinating the spare parts supply and distribution;

- Shortening lead times for ordering the spare parts and hiring support vessels; and

- Improving the reliability of wind turbines.

In order to improve the reliability level of wind turbines, a redundant structure for some critical components has been suggested in the literature (e.g., see [141]). Recently, wind turbine assembly manufacturers (such as SIEMENS, REpower, and Gamesa) have proposed a prototype design of six parallel-connected converter system to use in the harsh offshore environments. The benefits of applying this prototype design (i.e. improving the reliability, efficiency, and power output) have been discussed in [165]. The readers can also refer to $[20,43,50,59,86,87,132,148,151,173,186,209,216,221]$ for further studies on reliability/availability analysis of wind farms.

\subsection{Solution technique}

When the objectives are set and all necessary information is available, an optimization technique must be used to find out the optimal solution. In a broad classification, the maintenance optimization solution techniques are categorized into two types of qualitative and quantitative [190]. The qualitative techniques are subjective or judgmental and are based on estimates and opinions, while the quantitative techniques incorporate various mathematical models and statistical analysis. In this section, a generic list of all possible 
maintenance optimization solution techniques is developed, taking into account the techniques found in literature and adding the ones are missing.

- Operations research models (IP, MIP, NLP, DP)

Integer programming (IP) assumes that the decision variables take only integer values. Problem contexts that involve both integer and continuous decision variables are termed mixed-integer programming (MIP). Non-linear programming (NLP) is the method of solving problems involving a nonlinear objective function subject to linear or nonlinear constraints. Dynamic programming (DP) is a method for solving multí-stage decision problems by breaking them down into simpler sub-problems. Nilsson [195] proposed an MIP model to optimize the maintenance management of wind farms based on a linear cost function including the maintenance expenses and production losses. For further studies on operations research models, see $[41,47,50,55,69,71,77,100,168,197,200]$.

\section{- Stochastic models}

The O\&M optimization of wind turbines greatly depends on some stochastic factors such as wind speed and wave height. A stochastic model has the capability to incorporate key random factors to predict the system condition. Veldkamp [25] proposed a stochastic model to identify the important parameters affecting fatigue loads in wind turbines. Then, a cost minimization model was presented to determine the optimal failure probabilities and partial factors in the system. Recently, various stochastic models have been proposed to determine the optimal maintenance policy for wind turbines. The readers can refer to these references for further: [72, 81, 120, 127, 153, 158].

\section{- Markov models (discrete/continuous Markov model, semi Markov, hidden Markov)}

Markov model is a stochastic process with the property of being memoryless. In other words, a Markov model is a sequence of realized states that the transition probability to a state only depends on the current state and not on the history of states. Markov models are widely used for modeling the deterioration of a system with several degradation states, e.g. five states including ' good (0)', 'minor degradation (1)', 'advanced degradation (2)', 'major degradation (3)' and 'failure (4)'. At each state, the next time for inspection is updated based on the maintenance decisions for the current state. If a minimal repair is performed, the system will stay in "as-bad-as-old" condition, while an imperfect maintenance leads the system to a less degradation state. At the event of a failure (state ' 4 '), the system has to be replaced by a new one.

The deterioration process in wind turbine components can be modeled using a discrete or continuous Markov model. In discrete models, the component is observed at discrete time points, while in continuous models there is continuous observation. Byon and Ding [31] formulated an optimal maintenance model for multi-state deteriorating wind turbines using a partially observed Markov decision process with heterogeneous parameters. Ossai et al. [182] developed a six state Markov model to evaluate the impacts of wind turbine components maintenance on downtime and failure risks. The transition and maintenance rates at different lifecycle phases were determined using a calibrated survivability index. 
Abeygunawardane [209] in his $\mathrm{PhD}$ thesis proposed a Markov model for condition monitoring of wind turbine systems. In this study, a two-state model was presented for binary-state components (with two 'up' and 'down' states) and a three-state model was developed to include an intermediate state at which faults are detected.

In semi-Markov models, the transition rates to other states may change over the duration of a state and therefore, the inter-arrival times between subsequent states are not exponentially distributed. Su and Zhou [62] proposed a condition-based maintenance optimization model based on a semi Markov decision process in order to minimise the long-term discounted maintenance costs.

Hidden Markov model (HMM) is also being used to monitor the online SCADA data for fault detection purposes, especially when there is a lack of field failure data. The main feature of HMM is that, in a regular Markov model the states are directly visible to the observer but in an HMM only the sensor output is visible and the states are not directly visible.

For more references on Markov models, see [5, 32, 49, 70, 82,133, 210, 212].

\section{- Petri net model}

Petri net $(\mathrm{PN})$ model is a graphical and mathematical tool which was originally developed for the modeling and analysis of distributed systems with concurrency and resource sharing. As a graphical modeling tool, $\mathrm{PN}$ is composed of a set of places $(\mathrm{P})$, a set of transitions (T), and a set of directed arcs (A). The places represent conditions and are drawn as circles, the transitions represent events and are drawn as bars, and the arcs connect transitions to places and places to transitions. In the wind energy industry, PN model has been mainly applied to fault diagnosis and reliability evaluation of wind turbines. Yang et al. [46] proposed a novel PN model and reliability evaluation method for the hydraulic variable pitch system of a wind turbine. The proposed PN model not only described the structure, function and operation of the hydraulic pitch system with a graphic language, but also it could clearly express the logical relations among faults. Leigh and Dunnett [178] applied the PN approach to optimise maintenance processes of a wind turbine with three types of maintenance actions, namely periodic, conditional and corrective as well as the weather condition in order to determine the accessibility of the turbine. For further references on PN models, see [128, 161].

- Analytical models

Analytical model is a mathematical tool with a closed form solution, i.e., the solution to the equations describing any changes in the system is expressed as a mathematical analytic function. Feuchtwang and Infield [53] developed a closed form probabilistic model for estimating the expected delays caused by sea state during the maintenance process of offshore wind turbines. They applied the model to explore the impact of different parameters such as components' reliability, time to repair, and access constraints on two specific offshore sites. In another work, Mensah and Dueñas-Osorio [59] proposed an analytic model to evaluate the wind turbine system reliability as well as failure consequences. 


\section{- Simulation models}

Simulation model is one of the most flexible quantitative techniques that can be used for analyzing the reliability of complex systems. A simulation model has the capability to take into account all uncertainties exist in the field of wind farm O\&M as well as explore the feasibility of novel maintenance strategies. The principle of a simulation model is to generate various maintenance scenarios according to the stochastic variables of model and then to evaluate the quantities of interest (e.g. cost, availability, breakdowns) for each scenario. Byon et al. [37] developed a discrete-event system specification (DEVS) model for simulation of the wind farm O\&M. The authors implemented the simulation model under two main maintenance strategies, namely scheduled maintenance and conditionbased maintenance. The results showed that the condition-based maintenance policy enables operators to reduce the failure rate of wind turbines and increase the availability of wind farm. Benmessaoud et al. [69] used a simulation model to optimize the schedule and the type of maintenance actions applied to a wind farm. Their model was based on a cost minimization criterion aiming to determine the optimal maintenance strategy such that a greater availability and an increased power output were achieved in wind farm. Santos et al. [161] used a stochastic PN model coupled with Monte Carlo simulation (MCS) for modelling and optimization of an operation and maintenance strategy based on corrective maintenance replacements and imperfect age-based preventive maintenance repairs.

For more references on simulation models, see [82, 108, 146, 149, 160, 192].

\section{- Bayesian networks}

Bayesian network (BN) is a probabilistic graphical model representing the conditional dependencies between failure root causes and symptoms, i.e. given symptoms, the model is able to estimate the probabilities of the presence of various faults. BN model is recognized as an efficient tool for fault diagnosis and maintenance optimization of the wind turbines. Nielsen and Sørensen [44, 112] applied the BN model to optimize the risk-based maintenance decisions of offshore wind farms such that the cost of PM effort was balanced against the costs of corrective maintenance actions. For more references on BN model, see $[24,29,60,214]$.

\section{- Fuzzy models}

Fuzzy models are often used when the system dynamics are not precisely known, and the information is mainly based on experts' knowledge and expertise. Dinmohammadi and Shafiee [74] developed a fuzzy-FMEA failure mode and effects analysis (FMEA) approach for risk and failure mode analysis of offshore wind turbine systems. The information obtained from the experts was expressed using fuzzy linguistics terms and a grey theory analysis was proposed to incorporate the relative importance of the risk factors. Schlechtingen et al. [88] proposed a condition monitoring system for wind turbines using adaptive neuro-fuzzy interference systems (ANFIS). Cross and Ma [143] proposed a fuzzy logic-based inference system for condition monitoring and fault diagnosis of wind turbines.

\section{- Data mining techniques}


The SCADA system usually dumps large amounts of data from different sources being updated periodically. Very often, it is observed that the data collected from sensors is not all relevant or meaningful. In this case, data mining (DM) techniques can help wind farm operators to extract meaningful data and build models to find out how the changes in one or set of variables may affect the system performance. Thus, DM techniques can act as a key enabler in the design of a condition monitoring system for wind turbines. Kusiak and Verma [58] conducted a comparative analysis of various data-mining algorithms using the data collected at a large wind farm consisting seventeen wind turbines. Recently, in two PhD dissertations, Verma [207] and Zhang [208] used the data-mining techniques to monitor and optimize the performance of wind turbine systems based on the collected operational data and the fault logs from SCADA system. Depending upon the nature of wind turbine faults, the O\&M decisions were optimized. To read further on the applications of DM techniques in wind turbine O\&M, see [42, 64].

\section{- Intelligent-based models}

The dynamic nature of the environments in which wind turbines operate has led to the development of intelligent-based (IB) models. IB models play an important role in prediction of the system's residual life and currently are one of the key success factors in the implementation of condition monitoring systems for wind farms. IB models generally involve the development of powerful reasoning algorithms and prediction techniques such as machine learning (ML), Neural Network (NN), Artificial Intelligence (AI), and Expert Systems (ESs). Brandão et al. [48] introduced some applications of NNs to analyse the wind turbine condition and identify possible future failures. Zhao et al. [66] proposed an intelligent agent control approach to optimize the fatigue distribution of wind turbines in a large-scale offshore wind farm.

To read more on the applications of IB models in wind turbine O\&M, see [56, 78, 88, $108,122,130,183,225]$.

\section{- Multiple-objective models}

Even though single-objective maintenance optimization is attractive from the modeling point of view, it does not capture all important aspects of the wind energy industry. For example, maximizing the availability of a wind farm may not imply minimizing the O\&M costs. Sometimes when system reliability is maximized, the maintenance costs are still so high that they are not acceptable in practice. Multi-objective maintenance optimization is an underexplored area in wind energy. Jin et al. [81] proposed a multiple-objective optimization model to determine the equipment sizing, siting, and maintenance schedules of a wind-based distributed generation system such that the system cost was minimized and its reliability was maximized. Abdollahzadeh et al. [172] proposed a multi-objective based model to optimize the maintenance processes of a wind farm involved several different types of wind turbines. The proposed model attempts to maximize the expected rate of energy and minimize the total expected costs related to maintenance efforts.

For more references in this area, the readers can refer to $[85,114,156,173,191]$. 
A detailed distribution of the journal papers by operations research techniques used to find out the optimal solution is shown in Table 1.

\section{“Table (No. 1)"}

Table 1- Distribution of the journal papers by solution technique and maintenance strategy considered for optimization.

\section{Maintenance strategy}

A maintenance strategy includes a set of policies and actions that are used to "retain" or "restore" an equipment as well as the decision support system in which maintenance activities are planned. This section aims to review the O\&M strategies which are employed by wind farm operators and find out the possible gaps between current practices and benchmark goals. A detailed distribution of the journal papers by maintenance strategy is shown in Table 1.

\subsection{Maintenance policies}

One important research area in maintenance optimization is the study of various maintenance policies used to improve system availability. There are many possible ways to classify the current practices of maintenance in wind energy. In the reference [52], the authors studied the existing maintenance strategies in wind farms and then discussed the major challenges (e.g. site and seasonal asset disturbances, dependability and asset deterioration, diagnostic and prognostic) for an effective management of O\&M. From classical point of view, maintenance policies for wind farms can be categorized into two major classes: failure-based (reactive response) and proactive maintenance. The former is carried out when a failure oceurs in one of the components and the wind turbine shuts down. But, the latter is to either repair or replace the critical components according to a prescribed criterion (e.g. at pre-determined time intervals) in order to control the rate of degradation. From lifecycle point of view (i.e. from the design stage to end-of-life), EIThalji [198] divided the wind farm maintenance policies into six categories: design and development, production and construction, diagnostic, autonomous, proactive, and prognostics (predictive) maintenance.

In a broader classification, in this paper we categorize the maintenance policies applied to wind power systems into the following groups:

- Overhauling

Under this policy, a major overhaul (including re-design and/or replacement of critical equipment) is carried out after a long period of time (e.g. five years). Even though overhauling may be a possible solution for highly reliable wind turbines, it cannot be considered as a long-term approach for maintaining the wind farms with high rate of failure. Bell [237] reports that a wind turbine overhaul costs almost $20 \%$ of the initial investment. Moreover, it requires some special service vessels (e.g. heavy lift cranes) which makes the process technically unfeasible. 


\section{- Corrective (breakdown or reactive response) maintenance}

Under this policy, a repair action is carried out after a wind turbine failure or upon a severe decline in power production. The corrective maintenance $(\mathrm{CM})$ policy may be practical for small onshore wind farms with a few number of wind turbines, or for those offshore wind turbines located close to the shore in shallow waters. However, when considering future wind farms which are likely to be built in remote areas, this policy cannot be cost-effective [11]. In Opti-OWECS project, Kühn et al. [8, 236] showed that unplanned repair and maintenance of the failed wind turbines account for a significant portion of the annual O\&M costs. Kooijman et al. [14] studied the current state of maintenance for offshore wind turbines in the North Sea. The authors suggest that utilizing an optimum PM policy can potentially minimize the maintenance expenditures.

\section{- Routine inspections}

Most of the wind farms undergo a daily routine inspection during the operation, and afterwards, one major inspection every two to three weeks. Some defects such as leakage and corrosion can be detected through visual inspections. However, detection of many of faults like surface cracks on the blades, electric short circuits in generator, and overheating of the gearbox require using more sophisticated inspection methods such as non-destructive testing (NDT). NDT techniques such as acoustic emission, ultrasonic, radiography, thermographic, electromagnetic, and eddy current can provide quantitative information about the deteriorated condition of wind turbine components and structures.

\section{- Performance based PM (calendar or time based, age based, use based)}

This broad group of maintenance policies is described as the repair activities undertaken at specified dates (i.e., calendar or time based), or after a fix period of time depending on the age of components (i.e., age-based), or according to the total amount of electricity produced (i.e., operational-based) in order to reduce the likelihood of failure or the degradation rate of system. Karyotakis [203] identified two types of calendar based maintenance which are commonly applied to offshore wind farms: PM1 with one scheduled visit per operational year (typically during July), and PM2 with two scheduled visits (often during May and October). As an example, Horns Rev (also known as Horns Reef) offshore wind farm in the east coast of the North Sea undergoes PM2 program (http://www.dongenergy.com). First, a minor PM task is carried out during January and then a major PM is performed during the summer. The minor PM task usually takes two days and it costs about $1000 €$ for each wind turbine, whereas the major PM takes three days and it costs roughly around $1500 €$ per wind turbine. A main issue encountered in the ageor operational-based maintenance policies is to find out an optimum time interval or operation level for preventive replacement of critical assets so that system availability/reliability is maximized under given constraints. Su and Zhou [63] presented an optimum age-replacement maintenance policy for a wind turbine system with taking into account the economic dependence among components. A cost minimization model (including all costs related to repair, maintenance, replacement, and system breakdown) 
was developed and a branch and bound algorithm was utilized to find out the optimal solution. The readers can refer to these references for further: [21, 50, 154].

\section{- Failure-limit policy}

Failure-limit maintenance policy for wind farms is classified into various types. The most commonly used one is a number-dependent policy in which the maintenance decisions are made based on the number of system failures. For instance, the maintenance crew is sent to wind farm to carry out repairs or replacements when the number of failed wind turbines reaches a pre-specified number $m$, where $m=1,2, \ldots, N$, and $N$ denotes the total number of wind turbines in wind farm (for more see [89, 197]). The failure-limit maintenance policy can also be based on cost or failure likelihood criterion, i.e., a component undergoes PM action if the associated cost [failure likelihood] is less than a predetermined threshold; otherwise it is replaced by a new one [45].

- Reliability-centered, condition based, and predictive maintenance

Reliability centered maintenance (RCM) has been widely recognized and implemented in the wind energy industry [27, 115, 166, 229, 245]. RCM is used to optimize the maintenance decisions of a system while preventing its reliability level from dropping below a certain specified value. It involves maintaining the system functions, identifying the failure modes, prioritizing the potential risks, identifying PM requirements, and selecting the most appropriate maintenance tasks. RCM is usually applied to critical components/subsystems whose failures could result in catastrophic system failure or high loss of power production. To this aim, many different tools including the failure mode and effects analysis (FMEA), failure mode, effects and criticality analysis (FMECA), and fault tree analysis (FTA) are utilized (e.g., see [74, 204]). Fischer et al. [54] applied the RCM methodology to two types of Vestas wind turbines: V44-600kW and V90-2MW. A criticality analysis on the basis of failure frequency and incurred consequences was done for four critical subsystems, namely gearbox, generator, electrical system, and hydraulic system.

Condition based maintenance (CBM) is now the most extensively used policy in the wind energy industry and its related literature is vast. CBM employs continuous monitoring and inspection techniques to detect incipient faults early in their evolution and to determine any necessary maintenance tasks. On the other hand, CBM works on the current condition of each component and before it drops below a certain threshold, a preventive repair or replacement action is carried out.

The benefits of using CBM for wind turbines have been studied in some publications. Nilsson and Bertling [19] quantified the benefits of implementing CBM in onshore and offshore wind energy sectors using an LCC analysis. McMillan and Ault [18, 23] and McMillan [192] used the simulation techniques to evaluate the cost effectiveness of CBM in onshore wind farms. Wiggelinkhuizen et al. [26] evaluated the added value of applying CBM policy to offshore wind farms within a European project called CONMOW (CONdition Monitoring for Offshore Wind farms). Van Horenbeek et al. [94] proposed a stochastic simulation model to quantify the economic added value of applying an imperfect 
CBM policy to wind turbines. A case study on a wind turbine gearbox was used to illustrate the approach. Haddad et al. [103] proposed a model to evaluate the individualized maintenance policies for different system instances and then quantified the value of CBM at all points in time from prognostic indication to the end of the remaining useful life (RUL). The readers can also refer to [36, 62, 193] for further reading on CBM of wind turbines.

Predictive maintenance ( $\mathrm{PdM})$ includes 'the use of modern measurement and signal processing methods to accurately predict and diagnose system condition during operation'. $\mathrm{PdM}$ is often referred to as CBM in the wind energy industry, however, PdM uses current and prognostic information of components to optimally schedule maintenance actions, while CBM only uses current component state information. Recently, many articles have addressed the optimization of PdM decisions for wind farms. For some references on PdM optimization, the readers can refer to [42, 93, 215, 225].

\section{- Risk based maintenance}

Risk based maintenance (RBM) aims to reduce the overall risks associated with unexpected failures of wind turbines. The inspection and maintenance schedule is optimized on the basis of quantified risks caused by failure of components. The high-risk components (e.g. rotor blades, gearbox, and generator) are inspected and maintained with greater frequency, whereas for low-risk components (e.g. brake) the effort is minimized to reduce the total scope of work and cost of maintenance program. In three PhD thesis of Bharadwaj [196], Ramírez [199] and Nielsen [214], several optimum risk-based inspection methodologies have been proposed for offshore wind turbines. Sørensen [29] proposed a risk-based life cycle approach to optimize planning of maintenance in offshore wind farms. The developed approach is based on a pre-posterior Bayesian decision theory which takes into account various deterioration mechanisms such as fatigue, corrosion, wear and erosion. Nielsen and Sørensen [44] proposed an optimal RBM policy for an offshore wind turbine consisting of a single critical component. In their study, the costs related to inspection, repair and lost production under a periodic imperfect inspection policy were evaluated. For more references on RBM models, see [24, 47, 60, 73, 112, 135, 151, 167, 171, 182, 220].

- Group maintenance, opportunistic replacement

Under group maintenance policy, the components with similar operating conditions (such as electrical components) are identified and undergo an inspection and maintenance task together. In other words, a group maintenance policy provides a basis to combine maintenance activities and share the set-up costs with a number of components in the system. Such sharing strategy can reduce costs or may result in lower costs compared to the case when maintenance tasks are conducted separately for each component [163]. In opportunistic maintenance policy, an unplanned failure of a critical sub-system is considered as an opportunity to perform PM on other sub-systems. One prevalent type of this policy is an opportunistic block replacement policy in which upon a component failure, the whole system is preventively replaced by a new one. For some references on 
opportunistic maintenance optimization models, see $[38,51,55,118,131,132,162,164$, $172,173,185]$.

\subsection{Maintenance effectiveness}

Maintenance actions according to degree of restorability of the system are classified into three main categories. The first type of maintenance actions is minimal or as bad as old (ABAO), the second class is complete (perfect) or as good as new (AGAN), and the third class is known as imperfect maintenance. Let $\delta \in[0,1]$ denote the effectiveness of a maintenance action. In the ABAO case $(\delta=0)$, each repair action restores the system to the level it was just before the failure while in the AGAN case $(\delta=1)$, each repair action restores the system to the brand new state. The case $0<\delta<1$ corresponds to imperfect maintenance action in which operating condition of the system is restored to somewhere between AGAN and ABAO. The main advantage of using imperfect maintenance is that the degree of item restoration can be considered a decision variable. Several methods (e.g. the Brown and Proschan, improvement factor, virtual age models) have so far been developed in the literature to model imperfect maintenance. However, the application of these models in O\&M planning of wind turbines has been very limited (see [38, 51, 94, $134,152])$.

\section{Future research and concluding comments}

Even though the maintenance optimization is a relatively young discipline in the wind energy sector, a lot of research has already been done in this field. In the current paper, we proposed a classification framework for the study of inspection planning and maintenance optimization in wind energy industry. The proposed framework identifies various theoretical and practical issues, including the associated models, methods, and the strategies employed by maintenance operators to optimize inspection and replacement decisions in wind energy farms. Moreover, all the academic studies as well as industrial applications reported on the topic over the last two decades were identified, reviewed and analyzed. This classification scheme not only assists researchers in developing novel maintenance optimization methods, but also helps wind energy decision makers (owners/stakeholders) to find the models that fit their specific needs. Based on our findings, the following remarks can be concluded:

(a) Although many good maintenance optimization methods have been developed in literature, there still remains a big gap between academic models and application in practice. Many of the works have been published for mathematical purposes, whereas only very few number of industrial cases ( $6 \%$ of the total publications) have been presented. A shift from theoretical research to applied research is required. In order to achieve this shift, the availability of real data plays a significant role. Without accurate and precise information, maintenance decisions will be based on wrong or incomplete data which may lead to sub-optimal or even completely wrong solutions. The introduction of computerized maintenance management system (CMMS) such as e- 
maintenance technologies can provide a solution to this limitation. E-maintenance has the capability to provide high quality data at the right time in order to make the best decisions for O\&M of wind turbines.

(b) Despite the multitude of models available, there is little knowledge on what maintenance strategy is best suited to large-scale wind farms. In order to determine the most cost-effective maintenance strategy, a maintenance optimization model incorporating all information regarding system reliability, failure mechanisms, methods of failure detection, and inspection and maintenance costs is required. This can be achieved using a risk-based maintenance (RBM) approach. However, this approach is very computationally demanding compared to the classical replacement policies. So, there is a need to develop a methodology by integrating the classical approaches and structural reliability analysis that can be used in practice.

(c) Most of the optimization models take into account only one system criterion, either maximizing the reliability or minimizing the maintenance costs. However, in order to achieve the best performance, the reliability/availability measures and maintenance costs should be considered simultaneously. For this reason, the economic added value of optimal maintenance decision on overall performance of the wind farms (in terms of reduction in O\&M costs and enhancement in reliability) must be quantified.

(d) Failure modelling and maintenance planning of multi-unit wind turbine systems and structures are quite complicated. Initial (manufacturing-related) defects can occur in any of constituent components and depending on the loading conditions, they can grow to critical size resulting in collapse of the entire system. In many of the existing maintenance optimization models, it is assumed that the failure modes are connected to statistically independent components. However, many failure modes are correlated together due to, e.g. common (uncertain) loading. In many cases, it is imporatant to take this correlation into account. Moreover, some components are exposed to deterioration processes, e.g. fatigue and wear that propagate in time. This time dependency should be modelled, in particular when coupling to condition-based maintenance (CBM).

(e) 'Accessibility' is a very important factor for the ability to perform maintenance tasks on wind turbines. Uncertainty in weather conditions and sea state is a major factor which can affect the accessibility in a wind farm. Meteorological conditions have so far seldom been considered as a stochastic input (see [31, 32]). To improve the existing models, more accurate forecasting tools for wind/wave conditions are required to help the operators in making sound maintenance decisions.

\section{References}

[1] DEXIA asset management (2011) Fukushima accident: An inflection point for nuclear power, in favour of energy efficiency and renewable energy. SRI research paper, published at $12^{\text {th }}$ April 2011, http://sri.dexia-am.com. 
[2] WindEurope (2016) Wind in power, 2016 European Statistics. https://windeurope.org/aboutwind/statistics/european/wind-in-power-2016/, February 2017.

[3] Shafiee, M., Brennan, F. and Armada Espinosa, I. (2016) A parametric whole life cost model for offshore wind farms. International Journal of Life Cycle Assessment, 21(7), 961-975.

[4] Shafiee, M. (2015) Maintenance strategy selection problem: an MCDM overview. Journal of Quality in Maintenance Engineering 21(4), 378-402.

[5] Dawid, R., McMillan, D. and Revie, M. (2015) Review of Markov models for maintenance optimization in the context of offshore wind. In: Proceedings of the Annual Conference of the Prognostics and Health Management Society, 18-24 October, Coronado, California. , U.S.A., p. 269-279.

[6] Shafiee M. (2015) Maintenance logistics organization for offshore wind energy: current progress and future perspectives. Renewable Energy 77, 182-193.

[7] Baagøe-Engels, V. and Stentoft, J. (2016). Operations and maintenance issues in the offshore wind energy sector: An explorative study. International Journal of Energy Sector Management, 10(2), 245-265.

[8] Kühn, M., Bierbooms, W.A.A.M., Van Bussel, G.J.W., Cockerill, T.T., Harrison, R., Ferguson, M.C., Göransson, B., Harland, L.A., Vugts, J.H. and Wiecherink, R. (1999) Towards a mature offshore wind energy technologyguidelines from the opti-OWECS project. Wind Energy 2(1), 25-58.

[9] Ronold, K.O., Wedel-Heinen, J. and Christensen, C.J. (1999) Reliability-based fatigue design of wind-turbine rotor blades. Engineering Structures 21(12), 1101-1114.

[10] Ronold, K.O. and Larsen, G.C. (2000) Reliability-based design of wind-turbine rotor blades against failure in ultimate loading. Engineering Structures 22(6), 565-574.

[11] Verbruggen, T., Rademakers, L. and Roost, P. (2002) Maintenance manager to control operation and maintenance of offshore wind farms. International Journal of Environment and Sustainable Development 1(4), 370-379.

[12] Krokoszinski, H.J. (2003) Efficiency and effectiveness of wind farms keys to cost optimized operation and maintenance. Renewable Energy 28(14), 2165-2178.

[13] Van Bussel, G.J.W. and Bierbooms, W.A.A.M. (2003) The DOWEC offshore reference windfarm: analysis of transportation for operation and maintenance. Wind Engineering 27(5), 381-392.

[14] Kooijman, H.J.T., Noord, M. de., Uyterlinde, M.A., Wals, A.F., Herman, S.A. and Beurskens, H.J.M. (2004) Large scale offshore wind energy in the North Sea-A technology and policy perspective. Wind Engineering Journal 28(2), 143-156.

[15] Andrawus, J.A., Watson, J. and Kishk, M. (2007) Modelling system failures to optimise wind turbine maintenance. Wind Engineering 31(6), 503-522.

[16] Andrawus, J.A., Watson, J. and Kishk, M. (2007) Wind turbine maintenance optimisation: principles of quantitative maintenance optimisation. Wind Engineering 31(2), 101-110.

[17] Hansen, T. (2007) Wind turbines: designing with maintenance in mind. Power Engineering 111(5), p. 36.

[18] McMillan, D. and Ault, G.W. (2007) Quantification of condition monitoring benefit for offshore wind turbines. Wind Engineering, 31(4), 267-285.

[19] Nilsson J, Bertling L. (2007) Maintenance management of wind power systems using condition monitoring systems-life cycle cost analysis for two case studies. IEEE Transactions on Energy Conversion 22(1), 223-229.

[20] Tavner, P.J., Xiang, J., and Spinato, F. (2007) Reliability analysis for wind turbines. Wind Energy 10(1), 1-18.

[21] Andrawus, J.A., Watson, J., Kishk, M., and Gordon, H. (2008) Optimisation of wind turbine inspection intervals. Wind Engineering 32(5), 477-490.

[22] Coolen, F.P.A., Spinato, F., and Venkat, D. (2008) On modelling of grouped reliability data for wind turbines, IMA Journal of Management Mathematics 21(4), 363-372.

[23] McMillan, D. and Ault, G.W. (2008) Condition monitoring benefit for onshore wind turbines: sensitivity to operational parameters. IET Renewable Power Generation 2(1), 60-72.

[24] Ramírez, J.G.R., and Sørensen, J.D. (2008) Optimal risk-based inspection planning for offshore wind turbines. Journal of Steel Structures 8(4), 295-303.

[25] Veldkamp, D. (2008) A probabilistic evaluation of wind turbine fatigue design rules. Wind Energy 11(6), 655-72.

[26] Wiggelinkhuizen, E., Verbruggen, T., Braam, H., Rademakers, L., Jianping, X. and Watson, S. (2008) Assessment of condition monitoring techniques for offshore wind farms. Journal of Solar Energy Engineering 130(3), 030301.1-031020.12.

[27] Andrawus, J.A., Watson, J., Kishk, M. and Adam, A. (2009) The selection of suitable maintenance strategy for wind turbines. Wind Engineering 30(6), 471-486.

[28] Guo, H., Watson, S., Tavner, P. and Xiang, J. (2009) Reliability analysis for wind turbines with incomplete failure data collected from after the date of initial installation. Reliability Engineering and System Safety 94(6), 1057-1063. 
[29] Sørensen, J.D. (2009) Framework for risk-based planning of operation and maintenance for offshore wind turbines. Wind Energy 12(5), 493-506.

[30] Besnard, F. and Bertling, L. (2010) An approach for condition-based maintenance optimization applied to wind turbine blades. IEEE Transactions on Sustainable Energy 1(2), 77-83.

[31] Byon, E. and Ding, Y. (2010) Season-dependent condition-based maintenance for a wind turbine using a partially observed Markov decision process. IEEE Transactions on Power Systems 25(4), 1823-1834.

[32] Byon, E., Ntaimo, L. and Ding, Y. (2010) Optimal maintenance strategies for wind turbine systems under stochastic weather conditions. IEEE Transactions on Reliability 59(2), 393-404.

[33] Gray, C.S. and Watson, S.J. (2010) Physics of failure approach to wind turbine condition based maintenance. Wind Energy 13(5), 395-405.

[34] Herbert, G.M.J., Iniyan, S. and Goic, R. (2010) Performance, reliability and failure analysis of wind farm in a developing country. Renewable Energy 35(12), 2739-2751.

[35] Utne, I.B. (2010) Maintenance strategies for deep sea offshore wind turbines, Journal of Quality in Maintenance Engineering 16(4), 367-381.

[36] Yang, W., Tavner, P.J., Crabtree, C.J. and Wilkinson, M. (2010) Cost-effective condition monitoring for wind turbines. IEEE Transactions on Industrial Electronics 57(1), 263-271.

[37] Byon, E., Pérez, E., Ding, Y. and Ntaimo, L. (2011) Simulation of wind farm operations and maintenance using discrete event system specification. Simulation 87(12), 1093-1117.

[38] Ding, F. and Tian, Z. (2011) Opportunistic maintenance optimization for wind turbine systems considering imperfect maintenance actions. International Journal of Reliability, Quality and Safety Engineering 18(5), 463-482.

[39] Hameed, Z., Vatn, J. and Heggset, J. (2011) Challenges in the reliability and maintainability data collection for offshore wind turbines, Renewable Energy 36(8), 2154-2165.

[40] Hofmann, M. (2011) A review of decision support models for offshore wind farms with an emphasis on operation and maintenance strategies. Wind Engineering 35(1), 1-16.

[41] Kovács, A., Erdős, G., Viharos, Z.J. and Monostori, L. (2011) A system for the detailed scheduling of wind farm maintenance. CIRP Annals Manufacturing Technology 60(1), 497-501.

[42] Kusiak, A. and Verma, A. (2011) Prediction of status patterns of wind turbines: a data-mining approach. Journal of Solar Energy Engineering 133(1), 10 pages, DOI: 10.1115/1.4003188.

[43] Mabel, M.C., Raj, R.E. and Fernandez, E. (2011) Analysis on reliability aspects of wind power. Renewable and Sustainable Energy Reviews 15, 1210-1216.

[44] Nielsen, J.J. and Sørensen, J.D. (2011) On risk-based operation and maintenance of offshore wind turbine components. Reliability Engineering and System Safety 96(1), 218-229.

[45] Tian, Z., Jin, T., Wu, B. and Ding, F. (2011) Condition based maintenance optimization for wind power generation systems under continuous monitoring. Renewable Energy 36, 1502-1509.

[46] Yang, X., Li, J., Liu, W. and Guo, P. (2011) Petri net model and reliability evaluation for wind turbine hydraulic variable pitch systems. Energies 4(6), 978-997.

[47] Bharadwaj, U.R., Silberschmidt, V.V. and Wintle, J.B. (2012) A risk based approach to asset integrity management. Journal of Quality in Maintenance Engineering 18(4), 417-431.

[48] Brandão, R.F.M., Carvalho, J.A.B. and Barbosa, F.P.M. (2012) Neural networks for condition monitoring of wind turbines gearbox. Journal of Energy and Power Engineering 6(4), 638-644.

[49] D'Amico, G., Petroni, F. and Prattico, F. (2012) Reliability measures of second-order Semi-Markov chain applied to wind energy production. Journal of Renewable Energy, ID 368940, 6 pages.

[50] Deng, M.-N., Yu, Y.-H., Chen, L. and Zhao, H.-S. (2012) Optimal maintenance interval for wind turbine gearbox. Applied Mechanics and Materials 130-134, 112-118.

[51] Ding, F. and Tian, Z. (2012) Opportunistic maintenance for wind farms considering multi-level imperfect maintenance thresholds. Renewable Energy 45, 175-182.

[52] El-Thalji, I. and Liyanage, J.P. (2012) On the operation and maintenance practices of wind power asset: a status review and observations. Journal of Quality in Maintenance Engineering 18(3), 232-266.

[53] Feuchtwang, J. and Infield, D. (2012) Offshore wind turbine maintenance access: a closed-form probabilistic method for calculating delays caused by sea-state. Wind Energy, DOI: 10.1002/we.1539.

[54] Fischer, K., Besnard, F. and Bertling, L. (2012) Reliability-centered maintenance for wind turbines based on statistical analysis and practical experience. IEEE Transactions on Energy Conversion 27(1), 184-195.

[55] Hameed, Z. and Vatn, J. (2012) Role of grouping in the development of an overall maintenance optimization framework for offshore wind turbines. Proceedings of the IMechE, Part O, Journal of Risk and Reliability 226(6), 584-601. 
[56] Hameed, Z. and Wang, K. (2012) Development of optimal maintenance strategies for offshore wind turbine by using artificial neural network. Wind Engineering 36(3), 353-364.

[57] Hazi, A. and Gheorghiu, F. (2012) Wind turbines operation and maintenance: problems and solutions. Buletinul AGIR 3, 173-178.

[58] Kusiak, A. and Verma, A. (2012) A data-mining approach to monitoring wind turbines. IEEE Transactions on Sustainable Energy 3(1), 150-157.

[59] Mensah A.F. and Dueñas-Osorio, L. (2012) A closed-form technique for the reliability and risk assessment of wind turbine systems. Energies 5, 1734-1750.

[60] Ramírez, J.G.R. and Sørensen, J.D. (2012) Risk-based inspection planning optimisation of offshore wind turbines. International Journal of Structure \& Infrastructure Engineering 8(5), 473-481.

[61] Scheu, M., Matha, D., Hofmann, M. and Muskulus, M. (2012) Maintenance strategies for large offshore wind farms. Energy Procedia 24, 281-288.

[62] Su, C. and Zhou, X. (2012) Condition-based maintenance optimization for wind turbines based on semi-Markov decision process. Chinese Journal of Mechanical Engineering 48(2), 44-49.

[63] Su, C. and Zhou, X. (2012) Maintenance optimization for multi-component of wind turbine based on effective age. Journal of Southeast University (Natural Science Edition), 42(6), DOI: 10.3969/j.issn.1001-0505.2012.06.015.

[64] Verma, A. and Kusiak, A. (2012) Fault monitoring of wind turbine generator brushes: a data-mining approach. Journal of Solar Energy Engineering 134(2), 9 pages, DOI:10.1115/1.4005624.

[65] Wu, Y., Bing, H. and Lou, S. (2012) A unit maintenance scheduling model considering peak regulation pressure balance for power system containing wind farms. Dianwang Jishu/Power System Technology 36(11), 94-100.

[66] Zhao, R., Shen, W., Knudsen, T. and Bak, T. (2012) Fatigue distributíon optimization for offshore wind farms using intelligent agent control. Wind Energy 15(7), 927-944.

[67] Zhang, H., Yin, Y., Shen, H., He, J. and Zhao, S. (2012) Generator maintenance scheduling of large-scale wind power integration considering peak shaving. Dianli Xitong Zidonghua/Automation of Electric Power Systems 36(16), 25-30.

[68] Abouel-seoud, S.A. and Khalil, M.I. (2013) Cost optimization of maintenance scheduling for wind turbine gearbox components with assured reliability. World Journal Control Science and Engineering 1(1), 25-34.

[69] Benmessaoud, T., Mohammedi, K. and Smaili, Y. (2013) Influence of maintenance on the performance of a wind farm. Przeglad Elektrotechniczny 89(03a), 174-178.

[70] Besnard, F., Fischer, K. and L. Bertling L. (2013) A model for the optimization of the maintenance support organization for offshore wind farms. IEEE Transactions on Sustainable Energy 4(2), 443-450.

[71] Byon, E. (2013) Wind turbine operations and maintenance: a tractable approximation of dynamic decision making. IIE Transactions 45(11), 1188-1201.

[72] Carlos, S., Sánchez, A., Martorell, S. and Marton, I. (2013) Onshore wind farms maintenance optimization using a stochastic model. Mathematical and Computer Modelling 57, 1884-1890.

[73] De Andrade Vieira, R.J., Sanz-Bobi, M.A. (2013) Failure risk indicators for a maintenance model based on observable life of industrial components with an application to wind turbines. IEEE Transactions on Reliability, $62(3), 569-582$.

[74] Dinmohammadi, F. and Shafiee, M. (2013) A fuzzy FMEA risk assessment approach for offshore wind turbines. International Journal of Prognostics and Health Management 4, 59-68.

[75] Dinwoodie, I., McMillan, D., Revie, M., Dalgic, Y. and Lazakisd, I. (2013) Development of a combined operational and strategic decision support model for offshore wind. Energy Procedia 35, 157-166.

[76] Grecchi, M., Meroni, L. and Betteto, P. (2013) A new way for access and maintenance of offshore wind farms: the use of cableway to reduce cost and improve accessibility. Wind Engineering, 37(3), 281-303.

[77] Halvorsen-Weare, E.E., Gundegjerde, C., Halvorsen, I.B., Hvattum, L.M. and Nonås, L.M. (2013) Vessel fleet analysis for maintenance operations at offshore wind farms. Energy Procedia, 35, 167-176.

[78] Hameed, Z. and Wang, K. (2013) Clustering analysis to improve the reliability and maintainability of wind turbines with self-organizing map neural network. International Journal of Performability Engineering 9(3), 245-260.

[79] Hofmann, M. and Sperstad, I.B. (2013) NOWIcob-A tool for reducing the maintenance costs of offshore wind farms. Energy Procedia 35, 177-186.

[80] Huang, L., Fu, Y., Hu, R., Liu, L. (2013) Availability evaluation of offshore wind turbine considering operation and maintenance. Dianli Xitong Zidonghua/Automation of Electric Power Systems, 37(16), 13-17.

[81] Jin, T., Tian, Y., Zhang, C.W. and Coit, D.W. (2013) Multicriteria planning for distributed wind generation under strategic maintenance. IEEE Transactions on Power Delivery 28(1), 357-367.

[82] Kahrobaee, S. and Asgarpoor S. (2013) A hybrid analytical-simulation approach for maintenance optimization of deteriorating equipment: case study of wind turbines. Electric Power Systems Research 104, 80-86. 
[83] Li, H.Z., Jing, T. and Zhang, H. (2013) Arena-based modeling of the maintenance operation for a wind farm. Applied Mechanics and Materials 401-403, 2205-2208.

[84] Nguyen, T.H., Prinz, A., Friis $\emptyset$, T., Nossum, R. and Tyapin, I. (2013) A framework for data integration of offshore wind farms. Renewable Energy 60, 150-161.

[85] Pan, K., You, D.H. and Wang, K. (2013) Long-term multi-objective optimization dispatch and its evaluation in wind integrated power systems. Advanced Materials Research 732-733, 1033-1037.

[86] Perez-Canton, S. and Rubio-Romero, J.C. (2013) A model for the preventive maintenance scheduling of power plants including wind farms. Reliability Engineering and System Safety 119, 67-75.

[87] Pinar Pérez, J.M., García Márquez, F.P., Tobias, A. and Papaelias, M. (2013) Wind turbine reliability analysis. Renewable and Sustainable Energy Reviews 23, 463-472.

[88] Schlechtingen, M., Santos, I.F. and Achiche, S. (2013) Wind turbine condition monitoring based on SCADA data using normal behavior models. Part 1: System description. Applied Soft Computing 13(1), 259-270.

[89] Shafiee, M., Patriksson, M. and Strömberg, A.-B. (2013) An optimal number-dependent preventive maintenance strategy for offshore wind turbine blades considering logistics. Advances in Operations Research, ID 205847, 12 pages, DOI: 10.1155/2013/205847.

[90] Sinha, Y., Steel, J.A., Andrawus, J.A. and Gibson, K. (2013) A SMART software package for maintenance optimisation of offshore wind turbines. Wind Engineering 37(6), 569-577.

[91] Smarsly, K., Hartmann, D. and Law, K.H. (2013) An integrated monitoring system for life-cycle management of wind turbines. Smart Structures and Systems 12(2), 209-233.

[92] Smarsly, K., Hartmann, D. and Law, K.H. (2013) A computational framework for life-cycle management of wind turbines incorporating structural health monitoring. Structural Health Monitoring 12(4), 359-376.

[93] Tracht, K., Goch, G., Schuh, P., Sorg, M. and Westerkamp, J.F. (2013) Failure probability prediction based on condition monitoring data of wind energy systems for spare parts supply. CIRP Annals-Manufacturing Technology, $62(1), 127-130$.

[94] Van Horenbeek, A., Van Ostaeyen, J. and Pintelon, L. (2013) Quantifying the added value of an imperfectly performing condition monitoring system-Application to a wind turbine gearbox. Reliability Engineering and System Safety 111, 45-57.

[95] Wang, H.-B., Guo, R.-P., Jiang, Z.-M., Zhao, F. and Fan, C.-L. (2013) Generation maintenance scheduling based on minimum loss of load expectation considering significant wind power penetration. Dianli Xitong Baohu yu Kongzhi/Power System Protection and Control, 41 (4), pp. 26-32.

[96] Costa, Á.M., Roshan, G., Orosa, J.A. and Rodríguez-Fernández, Á. (2014) Case study of weather maintenance in wind power generation. Arabian Journal for Science and Engineering 39(7), 5615-5624.

[97] De Prada Gil, M., Gomis-Bellmunt, O. and Sumper, A. (2014) Technical and economic assessment of offshore wind power plants based on variable frequency operation of clusters with a single power converter. Applied Energy $125,218-229$.

[98] Ding, F., Tian, Z. and Amayri, A. (2014). Condition-based maintenance of wind power generation systems considering different turbine types and lead times. International Journal of Strategic Engineering Asset Management, 2(1), 63-79.

[99] Dinwoodie, I.A. and McMillan, D. (2014) Operational strategies for offshore wind turbines to mitigate failure rate uncertainty on operational costs and revenue. IET Renewable Power Generation 8(4), 359-366.

[100] Fathi Aghdam, F. and Liáo, H. (2014) Prognostics-based two-operator competition in proactive replacement and service parts procurement. Engineering Economist 59(4), 282-306.

[101] Fonseca, I., Farinha, J.T. and Barbosa F.M. (2014) Maintenance planning in wind farms with allocation of teams using genetic algorithms. IEEE Latin America Transactions 12(6), 1062-1070.

[102] Griffith, D.T., Yoder, N.C., Resor, B., White, J. and Paquette, J. (2014) Structural health and prognostics management for the enhancement of offshore wind turbine operations and maintenance strategies. Wind Energy $17(11), 1737-1751$.

[103] Haddad, G., Sandborn, P.A. and Pecht, M.G. (2014) Using maintenance options to maximize the benefits of prognostics for wind farms. Wind Energy 17(5), 775-791.

[104] Hofmann, M. and Sperstad, I.B. (2014) Will $10 \mathrm{MW}$ wind turbines bring down the operation and maintenance cost of offshore wind farms?. Energy Procedia 53(C), 231-238.

[105] Hong, Y., Tian, S.Y., Liu, Z.J. and Chen, F. (2014) Analysis of power planning model based on minimizing the operation and maintenance cost. Applied Mechanics and Materials 448-453, 2681-2686.

[106] Huang, B., Zhang, Y. and Yi, X. (2014) Operation and maintenance systems for offshore wind farms. Qinghua Daxue Xuebao/Journal of Tsinghua University 54 (4), 522-529. 
[107] Kang, J.S., Zhan, X.H., Xiao, L. and Zhang, X.A. (2014) Condition monitoring system of repaired gearboxes of wind turbine. Applied Mechanics and Materials 556-562, 2970-2973.

[108] Li, Y., Wang, J., Han, P. and Han, Y. (2014) Agent-Based modeling and simulation on the maintenance issue of the wind power generation. ICIC Express Letters, 8 (12), pp. 3541-3546.

[109] Ma, X.X., Su, L.X., Lv, S.D., Xu, M. and Huang, C.Y. (2014) Advanced zigbee routing strategy of offshore wind monitoring system. Applied Mechanics and Materials, 635-637, 648-653.

[110] Nejad, A.R., Gao, Z. and Moan, T. (2014) Fatigue reliability-based inspection and maintenance planning of gearbox components in wind turbine drivetrains. Energy Procedia 53(C), 248-257.

[111] Netland, O., Sperstad, I.B., Hofmann, M. and Skavhaug, A. (2014) Cost-benefit evaluation of remote inspection of offshore wind farms by simulating the operation and maintenance phase. Energy Procedia, 53(C), 239-247.

[112] Nielsen, J.S. and Sørensen, J.D. (2014) Methods for risk-based planning of O\&M of wind turbines. Energies 7(10), 6645-6664.

[113] Ortegon, K., Nies, L.F. and Sutherland, J.W. (2014) The impact of maintenance and technology change on remanufacturing as a recovery alternative for used wind turbines. Procedia CIRP 15, 182-188.

[114] Réthoré, P.-E., Fuglsang, P., Larsen, G.C., Buhl, T., Larsen, T.J. and Madsen, H.A. (2014) TopFarm: Multi-fidelity optimization of offshore wind farm. Wind Energy 17, 1797-1816.

[115] Sainz, J.A. and Sebastián, M.A. (2014) Maintenance centered on the reliability on wind turbines of low accessibility. Key Engineering Materials 615, 112-117.

[116] Sinha, Y., Steel, J.A., Andrawus, J.A. and Gibson, K. (2014) Significánce of effective lubrication in mitigating system failures - A wind turbine gearbox case study. Wind Engineering 38(4), 441-450.

[117] Sperstad, I.B., Halvorsen-Weare, E.E., Hofmann, M., Nonås, L.M., Stålhane, M. and Wu, M. (2014) A comparison of single- and multi-parameter wave criteria for accessing wind turbines in strategic maintenance and logistics models for offshore wind farms. Energy Procedia 53(C), pp. 221-230.

[118] Su, C. and Chen, W. (2014) Dynamic opportunistic maintenance optimization for wind turbine system based on rolling horizon approach. Jixie Gongcheng Xuebao/Journal of Mechanical Engineering 50(14), 62-68.

[119] Sun, J., Zhang, K. and Wu, Y.H. (2014) Structure optimum design based on maintenance and lifting equipment for wind turbine. Applied Mechanics and Materials, 684, 273-278.

[120] Tao, H.-Y. and Zhou, B.-H. (2014) Condition-based maintenance modeling of wind turbine based on stochastic process. Jisuanji Jicheng Zhizao Xitong/Computer Integrated Manufacturing Systems 20(6), 1416-1423.

[121] Wang, C.C., Gu, Y.J., Zhao, W.W., Han, Y.P. and Dong, Y.L. (2014) Research on preventive maintenance cycle decision of wind turbine. Advanced Materials Research 860-863, 383-388.

[122] Wang, K.-S., Sharma, V.S. and Zhang, Z.-Y. (2014) SCADA data based condition monitoring of wind turbines. Advances in Manufacturing 2(1), 61-69.

[123] Xie, Y. (2014) Offshore wind turbines operation and maintenance in China: A case study of Donghai Bridge offshore wind farm. Applied Mechanics and Materials, 448-453, 1871-1874.

[124] Yampikulsakul, N., Byon, E., Huang, S., Sheng, S. and You, M. (2014) Condition monitoring of wind power system with nonparametric regression analysis. IEEE Transactions on Energy Conversion 29(2), 288-299.

[125] Yang, M.L., Liu, S.M., Lv, Y.H., Zou, Y. and Ding, G.D. (2014) The real-time wind turbine fault diagnosis method based on safety evaluation model. Advanced Materials Research 953-954, 453-457.

[126] Zhang, K., Tong, S.H., Tian, Y. and Sun, J. (2014) The optimum design for clamping mechanism of wind power maintenance lifting platform. Applied Mechanics and Materials 684, 286-290.

[127] Zhang, P., Dai, L. and Liu, Y. (2014) Modelling operation of service vessels in offshore wind farms using stochastic activity networks. Ship Technology Research 61(1), 48-58.

[128] Zhang, Y., Huang, B. and Sang, Q. (2014) Modeling and analysis of maintenance processes for offshore wind farms based on GSPN. Qinghua Daxue Xuebao/Journal of Tsinghua University 54(7), 942-951.

[129] Zhang, Z.Y. (2014) Scheduling and routing optimization of maintenance fleet for offshore wind farms using DuoAco. Advanced Materials Research 1039, 294-301.

[130] Zhang, Z.-Y. and Wang, K.-S. (2014) Wind turbine fault detection based on SCADA data analysis using ANN. Advances in Manufacturing 2(1), 70-78.

[131] Zhao, H., Yan, S. and Zhang, X. (2014) Deterministic opportunistic replacement maintenance strategy for wind turbine. Taiyangneng Xuebao/Acta Energiae Solaris Sinica 35(4), 568-575.

[132] Zhao, H. and Zhang, L. (2014) Preventive opportunistic maintenance strategy for wind turbines based on reliability. Zhongguo Dianji Gongcheng Xuebao/Proceedings of the Chinese Society of Electrical Engineering 34(22), 3777-3783. 
[133] Zheng, X., Zhao, H., Liu, L. and Fu, Y. (2014) A combined maintenance strategy for offshore wind turbine considering accessibility. Dianwang Jishu/Power System Technology 38(11), 3030-3036.

[134] Zhao, H.-S., Zhang, X.-K. and Guo, W. (2014) Optimized maintenance strategy with imperfect repair for the gearbox of wind turbine. Dianli Xitong Baohu yu Kongzhi/Power System Protection and Control 42(10), 15-22.

[135] Zhou, A., Yu, D., Liu, J. and Li, R. (2014) Maintenance optimization for wind power generation equipment based on ontology and FTF. Zhongguo Jixie Gongcheng/China Mechanical Engineering 13, 1748-1754.

[136] Asensio, E.S., Pérez, J.M.P. and Márquez, F.P.G. (2015) Economic viability study for offshore wind turbines maintenance management. Advances in Intelligent Systems and Computing 362, 235-244.

[137] Astariz, S., Abanades, J., Perez-Collazo, C. and Iglesias, G. (2015) Improving wind farm accessibility for operation $\&$ maintenance through a co-located wave farm: Influence of layout and wave climate. Energy Conversion and Management 95, 229-241.

[138] Astariz, S. and Iglesias, G. (2015). Accessibility for operation and maintenance tasks in co-located wind and wave energy farms with non-uniformly distributed arrays. Energy Conversion and Management, 106, 1219-1229.

[139] Astariz, S., Perez-Collazo, C., Abanades, J. and Iglesias, G. (2015) Co-located wind-wave farm synergies (Operation \& Maintenance): A case study. Energy Conversion and Management 91, 63-75.

[140] Booma, J., Mahadevan, K. and Kannan, S. (2015) Minimum cost estimation of generation expansion planning incorporating wind power plant. ARPN Journal of Engineering and Applied Sciences 10(7), 2956-2961.

[141] Chen, M., She, S., Liu, X., Liu, G., Xiao, L. and Liu, D. (2015) Economical assessment on redundancy configuration of main transformers for offshore wind farm baséd on life cycle cost. Dianli Xitong Zidonghua/Automation of Electric Power Systems 39(14), 168-173.

[142] Costa, A.M., Fraguela, F., Orosa, J.A. and Pérez, J.A. (2015). A new procedure for wind energy systems maintenance design. Journal of Renewable and Sustainable Energy, 7(4), 043129.

[143] Cross, P. and Ma, X. (2015) Model-based and fuzzy logic approaches to condition monitoring of operational wind turbines. International Journal of Automation and Computing 12 (1), 25-34.

[144] Dai, L., Stålhane, M. and Utne, I. (2015) Routing and scheduling of maintenance fleet for offshore wind farms. Wind Engineering 39(1), 15-30.

[145] Dalgic, Y., Lazakis, I., Dinwoodie, I., McMillan, D. and Revie, M. (2015) Advanced logistics planning for offshore wind farm operation and maintenance activities. Ocean Engineering 101, 211-226.

[146] Dalgic, Y., Lazakis, I. and Turan, O. (2015) Investigation of optimum crew transfer vessel fleet for offshore wind farm maintenance operations. Wind Engineering 39(1), 31-52.

[147] Dalgic, Y., Lazakis, I., Turan, O. and Judah, S. (2015) Investigation of optimum jack-up vessel chartering strategy for offshore wind farm O\&M activities. Ocean Engineering 95, 106-115.

[148] de la Hermosa González-Carrato, R.R., Márquez, F.P.G., Alexander, K. and Papaelias, M. (2015) Methods and tools for the operational reliability optimisation of large-scale industrial wind turbines. Advances in Intelligent Systems and Computing 362, 1175-1188.

[149] Dinwoodie, I., Endrerud, O.-E., Hofmann, M., Martin, R. and Sperstad, I. (2015) Reference cases for verification of operation and maintenance simulation models for offshore wind farms. Wind Engineering 39(1), 1-14.

[150] Dumitrascu, A.-E., Lepadatescu, B., Dumitrascu, D.-I., Nedelcu, A. and Ciobanu, D.V. (2015) Reliability estimation of parameters of helical wind turbine with vertical axis. Scientific World Journal, art. no. 296762, DOI: $10.1155 / 2015 / 296762$.

[151] Florian, M. and Sørensen, J.D. (2015). Planning of operation \& maintenance using risk and reliability based methods. Energy Procedia, 80, 357-364.

[152] Florian, M. and Sørensen, J.D. (2015). Wind turbine blade life-time assessment model for preventive planning of operation and maintenance. Journal of Marine Science and Engineering, 3(3), 1027-1040.

[153] Gundegjerde, C., Halvorsen, I.B., Halvorsen-Weare, E.E., Hvattum, L.M. and Nonås, L.M. (2015) A stochastic fleet size and mix model for maintenance operations at offshore wind farms. Transportation Research Part C: Emerging Technologies 52, 74-92.

[154] Igba, J., Alemzadeh, K., Henningsen, K. and Durugbo, C. (2015) Effect of preventive maintenance intervals on reliability and maintenance costs of wind turbine gearboxes. Wind Energy, 18(11), 2013-2024.

[155] Jin, T., Tian, Z. and Xie, M. (2015) A game-theoretical approach for optimizing maintenance, spares and service capacity in performance contracting. International Journal of Production Economics 161, 31-43.

[156] Jin, T., Yu, Y. and Elsayed, E. (2015) Reliability and quality control for distributed wind/solar energy integration: a multi-criteria approach. IIE Transactions 47 (10), 1122-1138.

[157] Joschko, P., Widok, A.H., Appel, S., Greiner, S., Albers, H. and Page, B. (2015) Modeling and simulation of offshore wind farm O\&M processes. Environmental Impact Assessment Review 52, 31-39. 
[158] Kerres, B., Fischer, K. and Madlener, R. (2015). Economic evaluation of maintenance strategies for wind turbines: a stochastic analysis. IET Renewable Power Generation 9(7), 766-774.

[159] Liu, B. and An, Z. (2015) System reliability analysis of wind turbine gearbox considering component life dependency. Jixie Gongcheng Xuebao/Journal of Mechanical Engineering 51(10), 164-171.

[160] Pérez, E., Ntaimo, L. and Ding, Y. (2015) Multi-component wind turbine modeling and simulation for wind farm operations and maintenance. Simulation 91(4), 360-382.

[161] Santos, F., Teixeira, A.P. and Soares, C.G. (2015) Modelling and simulation of the operation and maintenance of offshore wind turbines. Proceedings of the Institution of Mechanical Engineers, Part O: Journal of Risk and Reliability 229(5), 385-393.

[162] Shafiee, M. and Finkelstein, M. (2015) An optimal age-based group maintenance policy for multi-unit degrading systems. Reliability Engineering and System Safety 134, 230-238.

[163] Shafiee, M. and Finkelstein, M. (2015) A proactive group maintenance policy for continuously monitored deteriorating systems: application to offshore wind turbines. Proceedings of the Institution of Mechanical Engineers, Part O: Journal of Risk and Reliability 229(5), 373-384.

[164] Shafiee, M., Finkelstein, M. and Bérenguer, C. (2015) An opportunistic condition-based maintenance policy for offshore wind turbine blades subjected to degradation and environmental shocks. Reliability Engineering and System Safety 142, 463-471.

[165] Shafiee, M., Patriksson, M., Strömberg, A.-B. and Tjernberg, L.B. (2015) Optimal redundancy and maintenance strategy decisions for offshore wind power converters. International Journal of Reliability, Quality and Safety Engineering 22(3), 1550015-1-1550015-24.

[166] Singh, S., Baglee, D., Michael, K. and Galar, D. (2015) Developing RCM strategy for wind turbines utilizing econdition monitoring. International Journal of Systems Assurance Engineering and Management 6(2), 150-156.

[167] Sinha, Y. and Steel, J.A. (2015) A progressive study into offshore wind farm maintenance optimisation using risk based failure analysis. Renewable and Sustainable Energy Reviews 42, 735-742.

[168] Stålhane, M., Hvattum, L. M. and Skaar, V. (2015). Optimization of routing and scheduling of vessels to perform maintenance at offshore wind farms. Energy Procedia 80, 92-99.

[169] Catterson, V.M., Mcmillan, D., Dinwoodie, I., Révie, M., Dowell, J., Quigley, J. and Wilson, K. (2015) An economic impact metric for evaluating wave height forecasters for offshore wind maintenance access. Wind Energy 19(2), 199-212.

[170] Le, B. and Andrews, J. (2016) Modelling wind turbine degradation and maintenance. Wind Energy 19(4), 571-591.

[171] Gintautas, T., Sørensen, J.D. and Vatne, S.R. (2016). Towards a risk-based decision support for offshore wind turbine installation and operation \& maintenance. Energy Procedia 94, 207-217.

[172] Abdollahzadeh, H., Atashgar, K. and Abbasi, M. (2016). Multi-objective opportunistic maintenance optimization of a wind farm considering limited number of maintenance groups. Renewable Energy 88, 247-261.

[173] Atashgar, K. and Abdollahzadeh, H. (2016). Reliability optimization of wind farms considering redundancy and opportunistic maintenance strategy. Energy Conversion and Management 112, 445-458.

[174] Baglee, D., Knowles, M., Kinnunen, S. K. and Galar, D. (2016). A proposed maintenance strategy for a wind turbine gearbox using condition monitoring techniques. International Journal Process Management and Benchmarking 6(3), 386-403.

[175] Kandukuri, S. T., Robbersmyr, K.G. and Karimi, H.R. (2016). Towards farm-level health management of offshore wind farms for maintenance improvements. The International Journal of Advanced Manufacturing Technology, 83(9-12), 1557-1567.

[176] Lahcen, B. (2016). Maintenance alternatives related to costs of wind turbines using finite state Markov Model. International Journal of Electrical, Computer, Energetic, Electronic and Communication Engineering, 10(1), 69-72.

[177] Lei, X. and Sandborn, P.A. (2016). PHM-based wind turbine maintenance optimization using real options. International Journal of Prognostics and Health Management, 7, 1-14.

[178] Leigh, J. M. and Dunnett, S. J. (2016). Use of Petri nets to model the maintenance of wind turbines. Quality and Reliability Engineering International, 32(1), 167-180.

[179] Li, X., Ouelhadj, D., Song, X., Jones, D., Wall, G., Howell, K. E. and Pertin, E. (2016). A decision support system for strategic maintenance planning in offshore wind farms. Renewable Energy, 99, 784-799.

[180] Martin, R., Lazakis, I., Barbouchi, S. and Johanning, L. (2016). Sensitivity analysis of offshore wind farm operation and maintenance cost and availability. Renewable Energy, 85, 1226-1236.

[181] Nicolas, T. and Dominique, M. (2016). Optimization of maintenance strategy of renewable energy production system (REPS) for minimizing production loss. International Journal on Interactive Design and Manufacturing, 10(3), 229-234. 
[182] Ossai, C.I., Boswell, B. and Davies, I.J. (2016). A Markovian approach for modelling the effects of maintenance on downtime and failure risk of wind turbine components. Renewable Energy, 96, 775-783.

[183] Pattison, D., Segovia Garcia, M., Xie, W., Quail, F., Revie, M., Whitfield, R.I. and Irvine, I. (2016). Intelligent integrated maintenance for wind power generation. Wind Energy, 19(3), 547-562.

[184] Pliego Marugán, A., García Márquez, F.P. and Pinar Pérez, J.M. (2016). Optimal maintenance management of offshore wind farms. Energies, 9(1), 46.

[185] Sarker, B.R. and Faiz, T.I. (2016). Minimizing maintenance cost for offshore wind turbines following multi-level opportunistic preventive strategy. Renewable Energy 85, 104-113.

[186] Zitrou, A., Bedford, T. and Walls, L. (2016) A model for availability growth with application to new generation offshore wind farms. Reliability Engineering and System Safety 152, 83-94.

[187] Kühn, M. (2001) Dynamics and design optimization of offshore wind energy convention systems. PhD thesis, Delft University of Technology, Delft, Netherlands.

[188] How, A. (2007) Design of a maintenance vessel for offshore wind farms to operate in the greater wash. Master thesis, Cranfield University, Cranfield, UK.

[189] Jong, F.P. de (2007) Development of a model to estimate O\&M costs for onshore wind farms. Master thesis, Department of Technology Management, Eindhoven University of Technology, The Netherlands.

[190] Andrawus J.A. (2008) Maintenance optimization for wind turbines. PhD thesis, Robert Gordon University, Aberdeen, UK

[191] Hilber, P. (2008) Maintenance optimization for power distribution systems. PhD thesis, Royal Institute of Technology, Stockholm, Sweden.

[192] McMillan, D. (2008) Techno-economic evaluation of condition monitoring and its utilisation for operation and maintenance of wind turbines using probabilistic simulation modeling. $\mathrm{PhD}$ thesis, Institute for Energy \& Environment, Department of Electronic \& Eelctrical Engineering, University of Strathclyde, Glasgow, UK.

[193] Saeed, A. (2008) Online condition monitoring system for wind turbine: case study. Master Thesis, Department of Electrical Engineering, Blekinge Institute of Technology, Karlskrona, Sweden.

[194] Besnard, F. (2009) On optimal maintenance management for wind power systems. Licentiate thesis, Chalmers University of Technology, Gothenburg, Sweden.

[195] Nilsson, J. (2009) On maintenance management of wind and nuclear power plants. Licentiate thesis, School of Electrical Engineering, Royal Institute of Technology (KTH), Stockholm, Sweden.

[196] Bharadwaj, U.R. (2010) Risk based life management of offshore structures and equipment. PhD thesis, Department of Civil and Building Engineering, Loughborough University, Leicestershire, UK.

[197] Ding, F. (2010) Comparative study of maintenance strategies for wind turbine systems. Master thesis, Department of Concordia Institute for Information System Engineering, Concordia University, Montreal, Quebec, Canada.

[198] El-Thalji, I. (2010) Systems dependability engineering for wind energy applications: challenges, concepts and system-level methodologies. Licentiate thesis, Linnaeus University, Växjö, Sweden.

[199] Ramírez, J.G.R. (2010) Reliability assessment and reliability-based inspection and maintenance of offshore wind turbines. PhD thesis, Aalborg University, Aalborg, Denmark.

[200] Amayri, A. (2011) Condition based maintenance of wind turbine systems considering different turbine types and lead times. Master thesis, Concordia Institute for Information System Engineering, Concordia University, Montreal, Quebec, Canada.

[201] Cantú, H.T. (2011) Life-cycle cost analysis for offshore wind farms: reliability and maintenance. O\&M cost drivers analysis. Master thesis, Department of Wind Energy, Gotland University, Gotland, Sweden.

[202] Ghanbari, A. and Oyelakin, M. (2011) Management system for operations and maintenance in offshore wind turbine plant. Master thesis, School of Business and Engineering, Halmstad University, Halmstad, Sweden.

[203] Karyotakis, A. (2011) On the optimisation of operation and maintenance strategies for offshore wind farms. PhD thesis, Department of Mechanical Engineering, University College London, London, UK.

[204] Manouchehrabadi, M.K. (2011) Reliable-centered maintenance (RCM), reliable and risk centered maintenance $(R R C M)$ in offshore wind farms. Master thesis, Department of Wind Energy, Gotland University, Gotland, Sweden.

[205] Parikh, N.D. (2012) Optimizing maintenance cost of wind farms by scheduling preventive maintenance and replacement of critical components using mathematical approach. Master thesis, Texas A\&M University, U.S.

[206] Thöns, S. (2012) Monitoring based condition assessment of offshore wind turbine support structures. PhD Thesis, Institute of Structural Engineering, Swiss Federal Institute of Technology Zurich, Switzerland.

[207] Verma, A. (2012) Performance monitoring of wind turbines: a data mining approach. PhD thesis, Department of Industrial Engineering, The University of Iowa, Iowa city, U.S.

[208] Zhang, Z. (2012) Performance optimization of wind turbines. PhD thesis, Department of Industrial Engineering, The University of Iowa, Iowa city, U.S. 
[209] Abeygunawardane, S.K. (2013) Probabilistic models for reliability assessment of ageing equipment and maintenance optimization. PhD thesis, Department of Electrical and Computer Engineering, National University of Singapore, Singapore.

[210] Besnard, F. (2013) On maintenance optimization for offshore wind farms. PhD thesis, Department of Energy and Environment Division of Electric Power Engineering, Chalmers University of Technology, Gothenburg, Sweden.

[211] Entezami, M. (2013) Novel operational condition monitoring techniques for wind turbine brake systems. $\mathrm{PhD}$ thesis, School of Electronic, Electrical and Computer Engineering, College of Engineering and Physical Sciences, University of Birmingham.

[212] Flory, J.A. (2013) Optimal replacement strategies for wind energy systems. PhD thesis, School of Engineering, University of Pittsburgh, U.S

[213] Khadabadi, M.A. (2013) Value-centric approaches to design, operations and maintenance of wind turbines. MSc thesis, Purdue University, U.S.

[214] Nielsen, J.S. (2013) Risk-based operation and maintenance of offshore wind turbines. PhD thesis, Faculty of Engineering and Science, Aalborg University, Aalborg, Denmark.

[215] Van Horenbeek, A. (2013) Information-based maintenance optimization with focus on predictive maintenance. $\mathrm{PhD}$ thesis, Faculty of Engineering Science, KU Leuven, Belgium.

[216] Kahrobaee, S. (2014) Reliability modeling and evaluation of distributed energy resources and smart power distribution systems. PhD thesis, University of Nebraska, Lincoln, U.S.

[217] Nguyen, T.H. (2014) Offshore wind data integration. PhD thesis, Faculty of Engineering and Science, University of Agder, Norway.

[218] Ruiz de la Hermosa, R. (2014) Novel approaches for maintenance management on wind turbines. PhD thesis, University of Castilla-La Mancha, Spain.

[219] Cao, J. (2015). Operation and maintenance of offshore wind farms. MSc Thesis, Delft University of Technology, Netherland.

[220] Bangalore, P. (2016). Load and risk based maintenance management of wind turbines. PhD thesis, Chalmers University of Technology, Gothenburg, Sweden.

[221] Einarsson, S. (2016). Wind turbine reliability modelling. MSc Thesis, Reykjavik, University, Iceland.

[222] Hussain, A. (2016). Simplified representation of degradation, inspection and maintenance in a strategic decision support tool for offshore wind operation and maintenance, MSc Thesis, University of Tromsø, Norway.

[223] Sinha, Y. (2016). Optimisation of offshore wind farm maintenance, PhD Thesis, Robert Gordon University, UK.

[224] Christensen, P. and Thøgersen, M.L. (2004). Maintenance planning for off-shore wind turbines by means of Bayesian networks. In: Decision analysis for reliability assessment. ed. T. Bedford; T. Christensen; H. Procaccia. Høvik : Det Norske Veritas, p. 107-111.

[225] Tian, Z., Ding, Y. and Ding, F. (2011) Maintenance optimization of wind turbine systems based on intelligent prediction tools. In: Innovative computing methods, SCI 357 (Eds. Nedjah et al.), pp. 53-71, Springer-Verlag, Berlin, Germany.

[226] Tavner, P. (2012) Offshore Wind Turbines: reliability, availability and maintenance. Renewable Energy series, vol. 13, The Institution of Engineering and Technology, London, UK

[227] Byon, E., Ntaimo, L., Singh, C. and Ding, Y. (2013) Wind energy facility reliability and maintenance. In: Handbook of Wind Power Systems (Eds. Pardalos et al.), pp. 639-672, Springer-Verlag, Berlin, Germany.

[228] Nunes, E., Telhada, J. and Carvalho, M. (2014) Estimating maintenance costs of a wind turbine pitch control system. IAENG Transactions on Engineering Sciences, pp. 193-202, Taylors \& Francis, London, UK.

[229] McMillan, D. and Ault, G. W. (2014). Towards reliability centred maintenance of wind turbines. In: Reliability Modeling and Analysis of Smart Power Systems, pp. 183-194, Springer, India.

[230] Endrerud, O.E.V. and Liyanage, J.P. (2015). Decision support for operations and maintenance of offshore wind parks, In Engineering Asset Management-Systems, Professional Practices and Certification. pp. 1125-1139: Springer International Publishing.

[231] Pérez, J. M. P., Asensio, E. S. and Márquez, F. P. G. (2015). Economic viability analytics for wind energy maintenance management, In: Advanced Business Analytics, pp. 39-54, Springer International Publishing, Switzerland.

[232] Hogg, S., Kazemtabrizi, B. and Williams, R. (2016). Assessment of operation and maintenance strategies. UK Wind Energy Technologies, Taylor \& Francis, New York.

[233] Nabati, E. G. and Thoben, K. D. (2016). Improving wind turbine maintenance activities by learning from various information flows available through the wind turbine life cycle. In: Dynamics in Logistics, pp. 147-150: Springer International Publishing, Switzerland. 
[234] Oelker, S., Lewandowski, M., Alla, A. A. and Thoben, K. D. (2016). Preactive maintenance-A modernized approach for efficient operation of offshore wind turbines. In: Dynamics in Logistics, pp. 323-331, Springer International Publishing, Switzerland.

[235] Santos, F.P., Teixeira, Â.P. and Soares, C.G. (2016). Operation and maintenance of floating offshore wind turbines. In: Floating Offshore Wind Farms, pp. 181-193, Springer International Publishing, Switzerland.

[236] Kühn, M., Cockerill, T.T., Harland, L.A., Harrison, R., Schöntag, C., Van Bussel, G.J.W., and Vugts, J.H. (1998) Opti-OWECS final report: vol. 2-Methods assisting the design of offshore wind energy conversion systems. Delft University of Technology, Delft, Netherlands.

[237] Bell, B. (2006) Wind turbine reliability and service improvements. Sandia National Laboratories, National Renewable Energy Laboratory (NREL), American Wind Energy Association, Albuquerque, California, New Mexico, U.S.

[238] Walford, C.A. (2006) Wind turbine reliability: understanding and minimizing wind turbine operation and maintenance costs. Sandia National Laboratories, National Renewable Energy Laboratory (NREL), Albuquerque, New Mexico, USA.

[239] Byon, E. (2007) On robust optimization of wind farm maintenance and operation under uncertainty. ISEN 689 Project report.

[240] Poore, R., and Walford C. (2008) Development of an operations and maintenance cost model to identify cost of energy savings for low wind speed turbines. Technical Report NREL/SR-500-40581, National Renewable Energy Laboratory (NREL), Albuquerque, New Mexico, USA.

[241] Laakso, T., Holttinen, H., Ronsten, G., Tallhaug, L., Horbaty, R., Baring-Gould, I., Lacroix, A., Peltola, E. and Tammelin, B. (2010) State-of-the-art of wind energy in cold climates. Working Papers 152, VTT Technical Research Centre of Finland. Available online: http://arcticwind.vtt.fi.

[242] Pettersson, L., Andersson, J.-O., Orbert, C. and Skagerman, S. (2010) RAMS-database for wind turbines Pre-study. Elforsk report 10:67. Available online: www.elforsk.se.

[243] ReliaWind consortium (2011) Optimising design, operation and maintenance for new generations of wind energy systems. Research Monograph, Durham University. Available online: www.reliawind.eu.

[244] Bertling, L. and Wennerhag, P. (2012) Wind turbine operation and maintenance: survey of the development and research needs. Elforsk report 12:41. Available online: www.elforsk.se.

[245] Fischer, K. (2012) Maintenance management of wind power systems by means of reliability-centred maintenance and condition monitoring systems. Project report. Division of Electric Power Engineering, Department of Energy and Environment Chalmers University of Technology, Gothenburg, Sweden.

[246] GAMESA (2013) Operation and maintenance: Gamesa services. Available online: www.gamesacorp.com.

[247] GL Garrad Hassan (2013) A guide to UK offshore wind operations and maintenance. Scottish Enterprise and The Crown Estate, UK.

[248] Maples, B., Saur, G., Hand, M., Pietermen, R.V.D. and Obdam T. (2013) Installation, operation, and maintenance strategies to reduce the cost of offshore wind energy. Technical Report NREL/TP-5000-57403, National Renewable Energy Laboratory (NREL), Albuquerque, New Mexico, USA.

[249] Griffith, D.T. (2015) Structural health and prognostics management for offshore wind plants: final report of Sandia $R \& D$ activities. Sandia National Laboratories, Albuquerque, New Mexico, California, U.S.A.

[250] Sheng (2015) Wind turbine gearbox reliability database, condition monitoring, and O\&M research update. National Renewable Energy Laboratory (NREL), U.S.A.

[251] Newman, M. (2015). Operations and maintenance in offshore wind: key issues 2015/2016. Available at: https://ore.catapult.org.uk/wp-content/uploads/2016/05/Operations-and-maintenance-in-offshore-wind.-Key-issuesfor-2015-16-1.pdf (accessed on 7/11/2016)

[252] MEGAVIND (2016) Strategy for extending the useful lifetime of a wind turbine. https://megavind.windpower.org/.

[253] Sperstad, I.B., Stålhane, M., Dinwoodie, I., Endrerud, O.E.V., Martin, R. and Warner, E. (2016). Testing the robustness of optimal vessel fleet selection for operation and maintenance of offshore wind farms. SINTEF, Trondheim, Norway, pp. 1-13.

[254] Nelson, V. and Starcher, K. (2011) Introduction to Renewable Energy, Second Edition, CRC Press, Taylor \& Francis Group. 


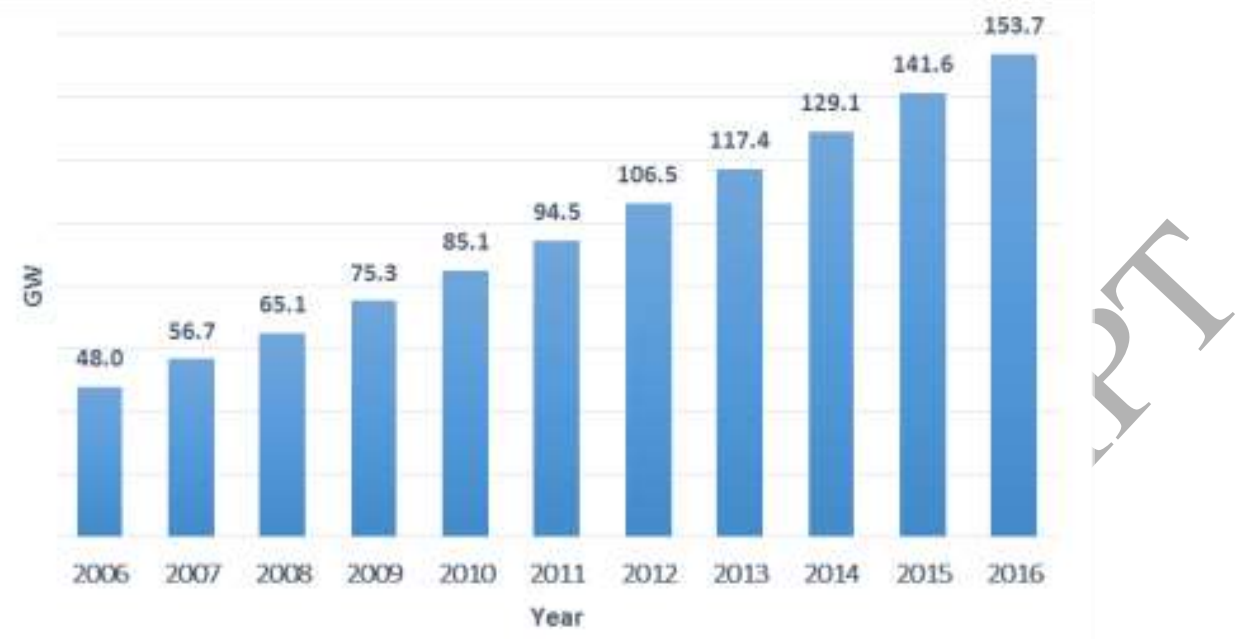

Figure 1. Cumulative installations of wind power in the EU during 2006-2016 [2].

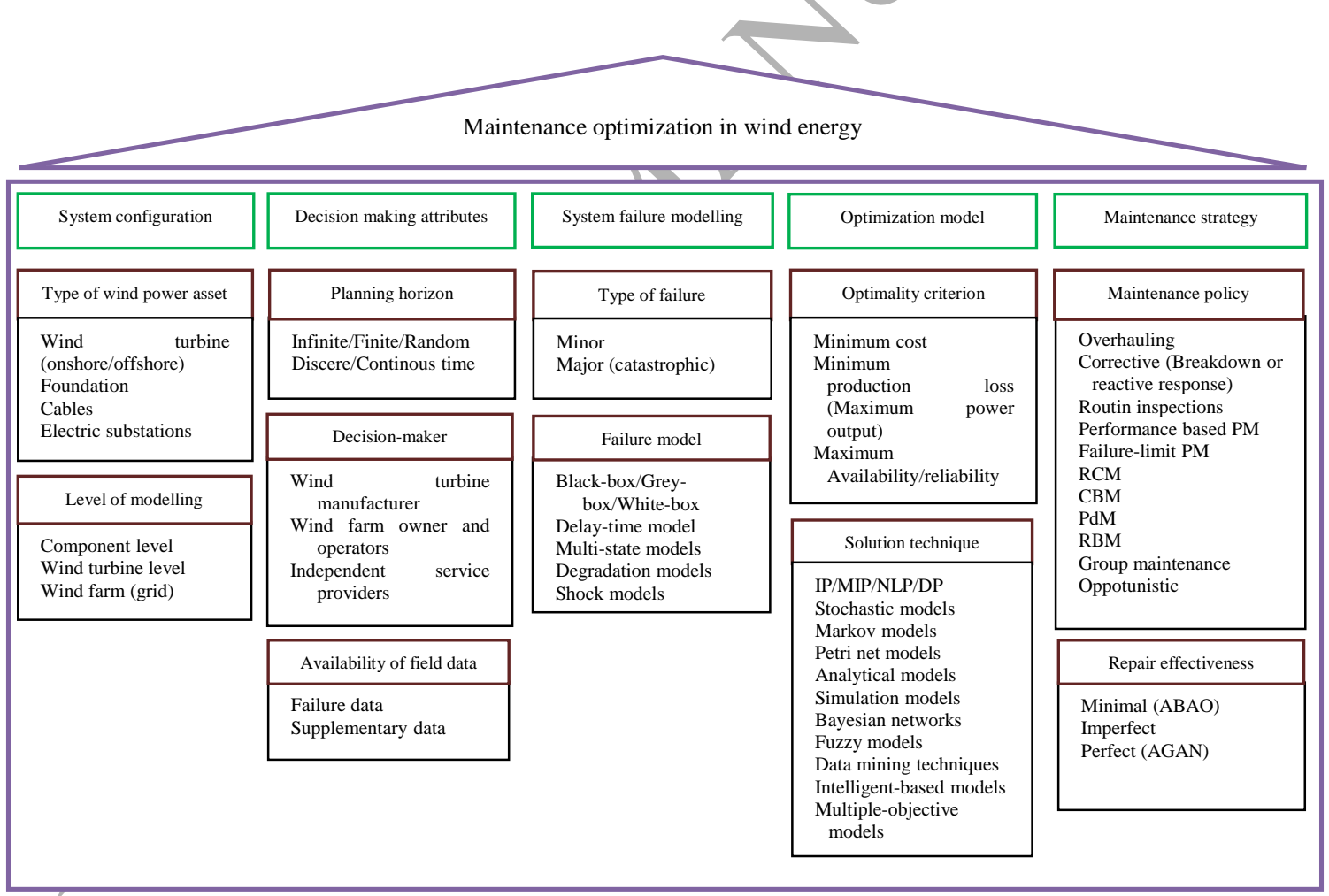

Figure 2. The classification framework proposed for the study. 


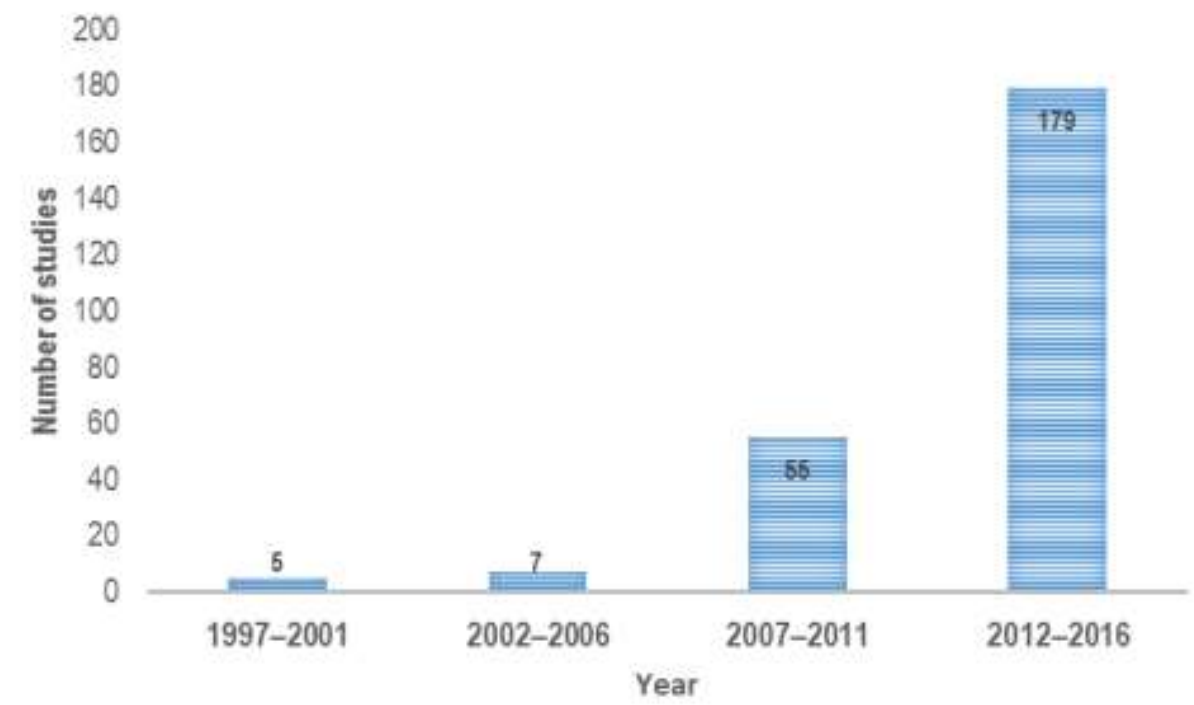

Figure 3. Distribution of the studies by year of publication (1997-2016).

Table 1- Distribution of the journal papers by solution technique and maintenance strategy considered for optimization.

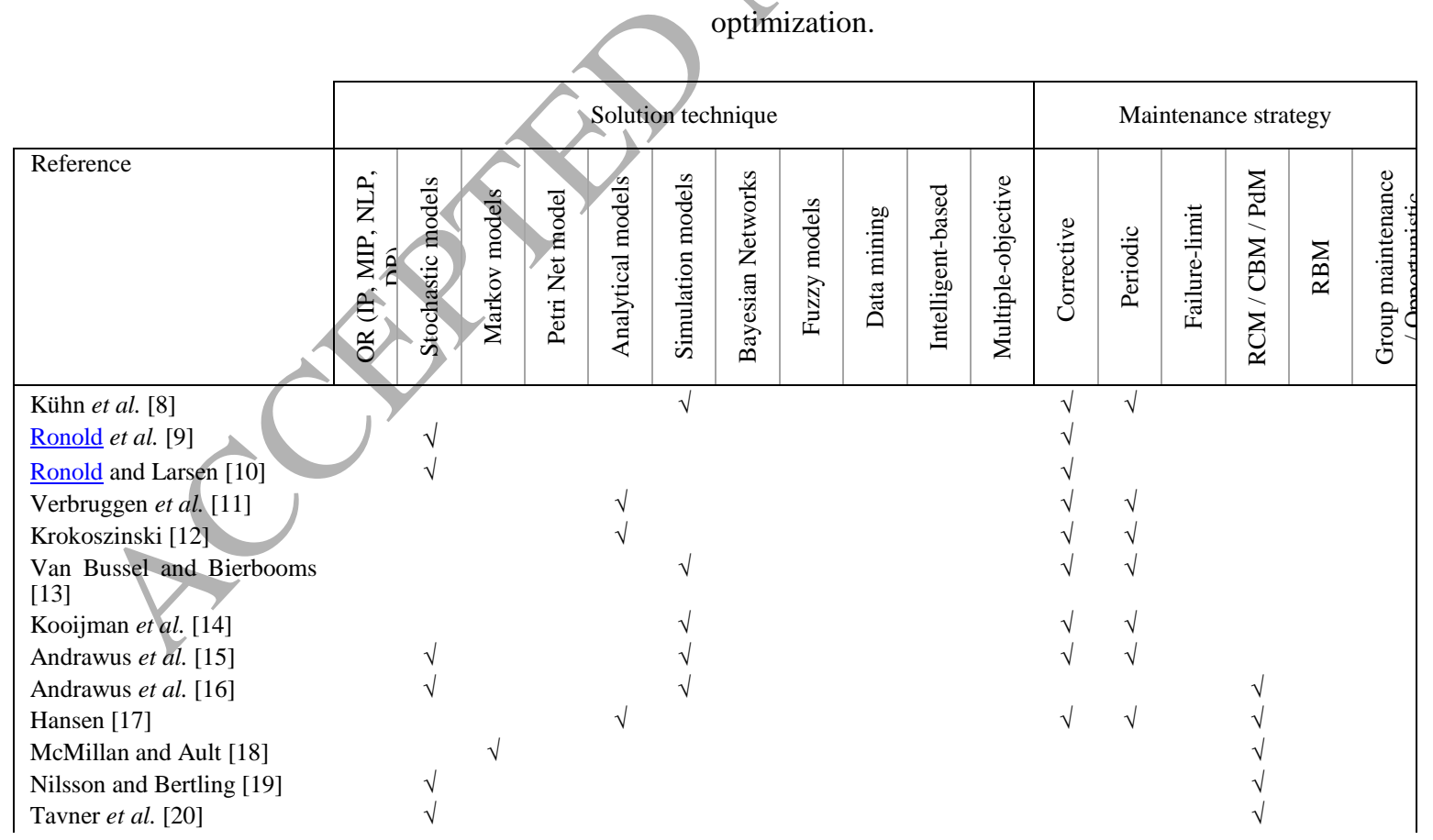


Andrawus et al. [21]

Coolen et al. [22]

McMillan and Ault [23]

Ramírez and Sørensen [24]

Veldkamp [25]

Wiggelinkhuizen et al. [26]

Andrawus et al. [27]

Guo et al. [28]

Sørensen [29]

Besnard and Bertling [30]

Byon and Ding [31]

Byon et al. [32]

Gray and Watson [33]

Herbert et al. [34]

Utne [35]

Yang et al. [36]

Byon et al. [37]

Ding and Tian [38]

Kovács et al. [41]

Kusiak and Verma [42]

Mabel et al. [43]

Nielsen and Sørensen [44]

Tian et al. [45]

Yang et al. [46]

Bharadwaj et al. [47]

Brandão et al. [48]

D'Amico et al. [49]

Deng et al. [50]

Ding and Tian [51]

Feuchtwang and Infield [53]

Fischer et al. [54]

Hameed and Vatn [55]

Hameed and Wang [56]

Hazi and Gheorghiu [57]

Kusiak and Verma [58]

Mensah and Dueñas-Osorio

[59]

Ramírez and Sørensen [60]

Scheu et al. [61]

$\mathrm{Su}$ and Zhou [62]

$\mathrm{Su}$ and Zhou [63]

Verma and Kusiak [64]

Wu et al. [65]

Zhao et al. [66]

Zhang et al. [67]

Abouel-seoud and Khalil

[68]

Benmessaoud et al. [69]

Besnard et al. [70]

Byon [71]

Carlos et al. [72]

De Andrade Vieira and $\sqrt{ }$

Sanz-Bobi [73]

Dinmohammadi and Shafiee

[74]

Dinwoodie et al. [75]

Grecchi et al. [76]

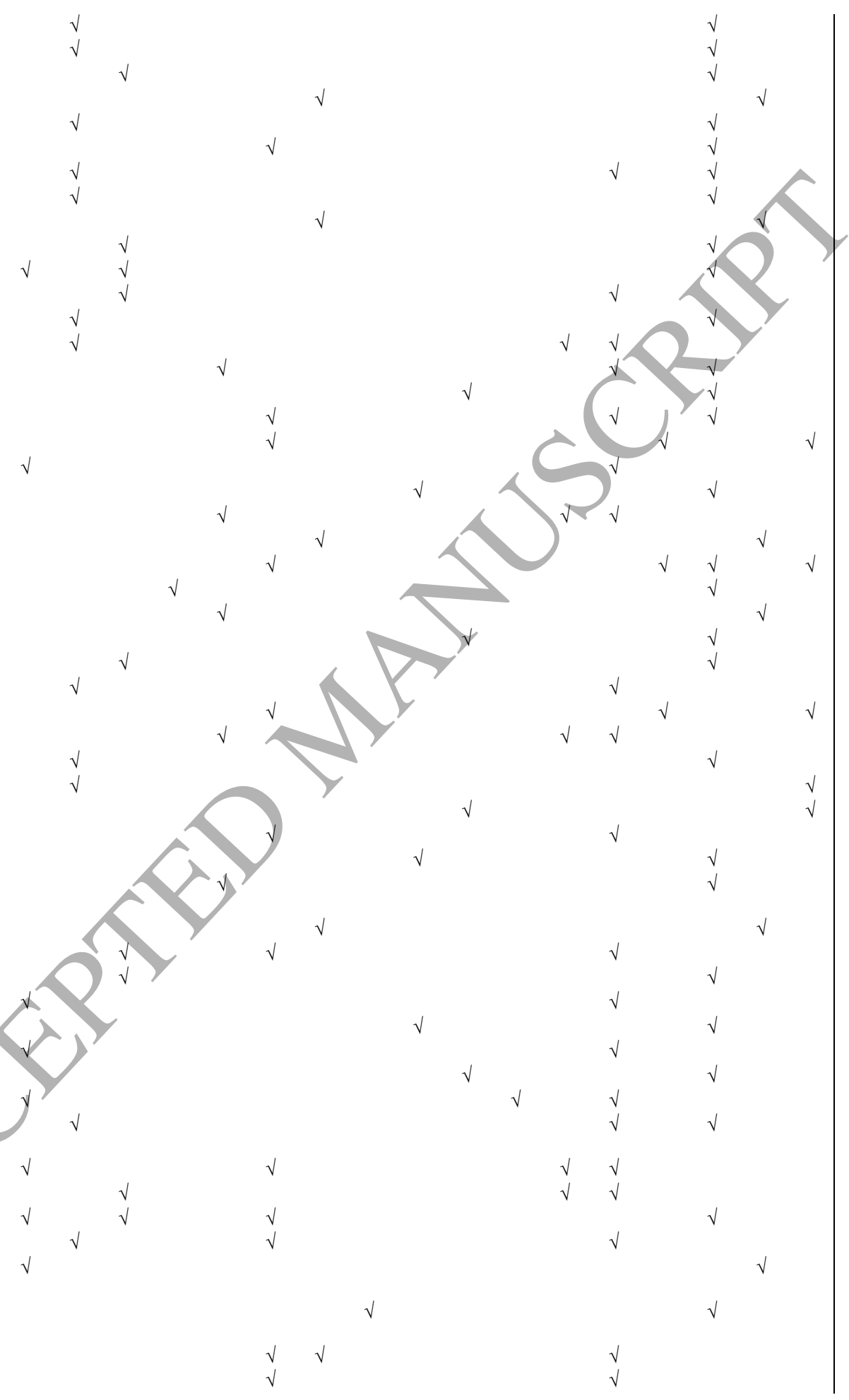


Halvorsen-Weare et al. [77]

Hameed and Wang [78]

Hofmann and Sperstad [79]

Huang et al. [80]

Jin et al. [81]

Kahrobaee and Asgarpoor

[82]

Li et al. [83]

Nguyen et al. [84]

Pan et al. [85]

Perez-Canton and Rubio-

Romero [86]

Schlechtingen et al. [88]

Shafiee et al. [89]

Sinha et al. [90]

Smarsly et al. [91]

Smarsly et al. [92]

Tracht et al. [93]

Van Horenbeek et al. [94]

Wang et al. [95]

Costa et al. [96]

De Prada Gil et al. [97]

Ding et al. [98]

Dinwoodie and McMillan

[99]

Fathi Aghdam and Liao

[100]

Fonseca et al. [101]

Griffith et al. [102]

Haddad et al. [103]

Hong et al. [105]

Kang et al. [107]

Li et al. [108]

Ma et al. [109]

Nejad et al. [110]

Netland et al. [111]

Nielsen and Sørensen [112]

Ortegon et al. [113]

Réthoré et al. [114]

Sainz and Sebastián [115]

Sinha et al. [116]

Sperstad et al. [117]

Su and Chen [118]

Sun et al. [119]

Tao and Zhou [120]

Wang et al. [121]

Wang et al. [122]

Yampikulsakul et al. [124]

Yang et al. [125]

Zhang et al. [127]

Zhang et al. [128]

Zhang [129]

Zhang and Wang [130]

Zhao et al. [131]

Zhao and Zhang [132]

Zheng et al. [133]

Zhao et al. [134]

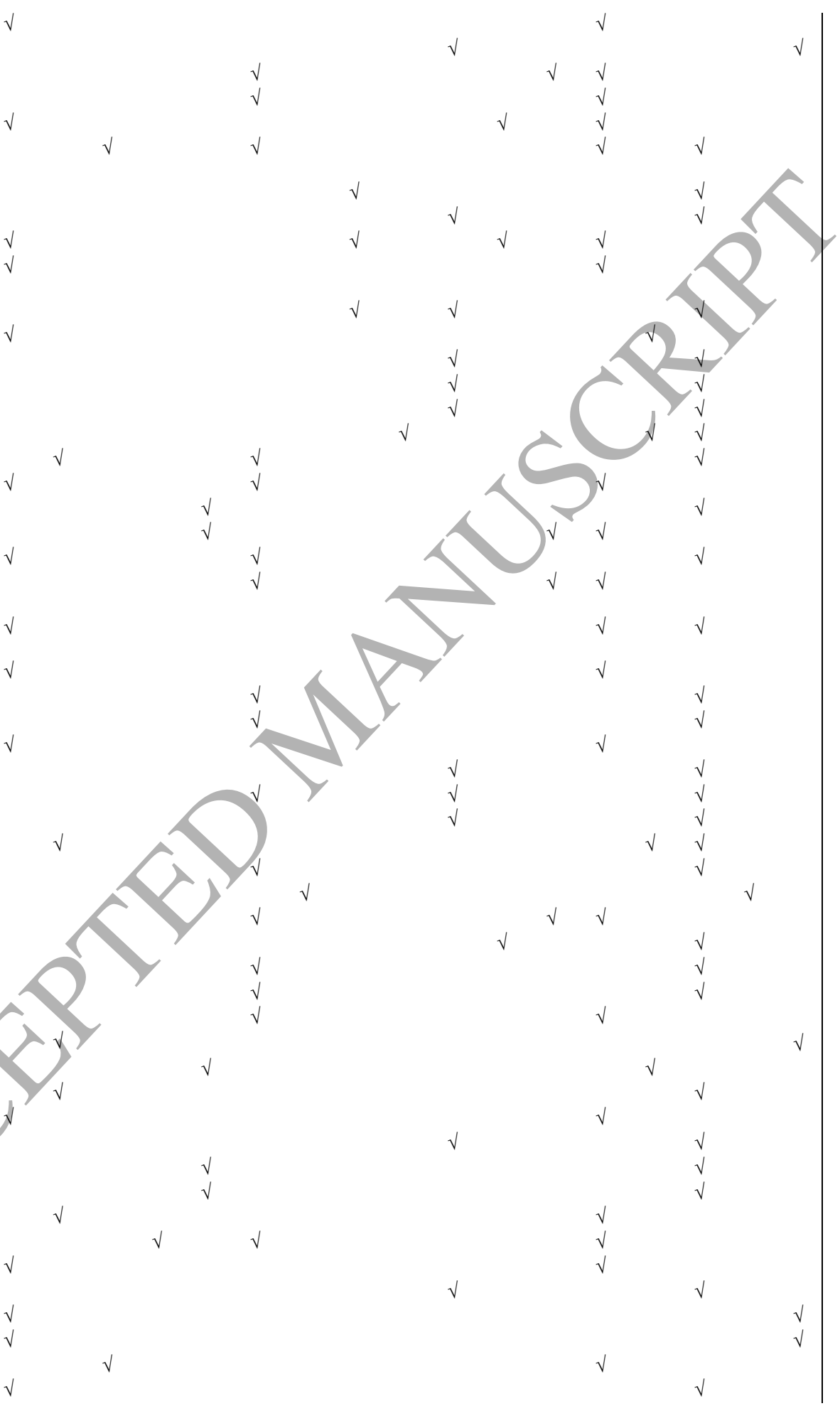


Zhou et al. [135]

Asensio et al. [136]

Astariz et al. [137]

Astariz et al. [138]

Astariz et al. [139]

Booma et al. [140]

Chen et al. [141]

Costa et al. [142]

Cross and Ma [143]

Dai et al. [144]

Dalgic et al. [145]

Dalgic et al. [146]

Dalgic et al. [147]

de la Hermosa González-

Carrato et al. [148]

Dinwoodie et al. [149]

Dumitrascu et al. [150]

Florian and Sørensen [151]

Florian and Sørensen [152]

Gundegjerde et al. [153]

Igba et al. [154]

Jin et al. [155]

Jin et al. [156]

Joschko et al. [157]

Kerres et al. [158]

Liu and An [159]

Pérez et al. [160]

Santos et al. [161]

Shafiee and Finkelstein $\sqrt{ } \sqrt{ }$

[162]

Shafiee and Finkelstein $\sqrt{ } \quad \sqrt{ }$

[163]

Shafiee et al. [164]

Shafiee et al. [165]

Singh et al. [166]

Sinha and Steel [167]

Stålhane et al. [168]

Catterson et al. [169]

Le and Andrews [170]

Gintautas et al. [171]

Abdollahzadeh et al. [172]

Atashgar

and

Abdollahzadeh [173]

Baglee et al. [174]

Lahcen [176]

Lei and Sandborn [177]

Leigh and Dunnett [178]

Li et al. [179]

Martin et al. [180]

Nicolas and Dominique

[180]

Ossai et al. [182]

Pattison et al. [183]

Pliego Marugán et al. [184]

Sarker and Faiz [185]

Zitrou et al. [186]

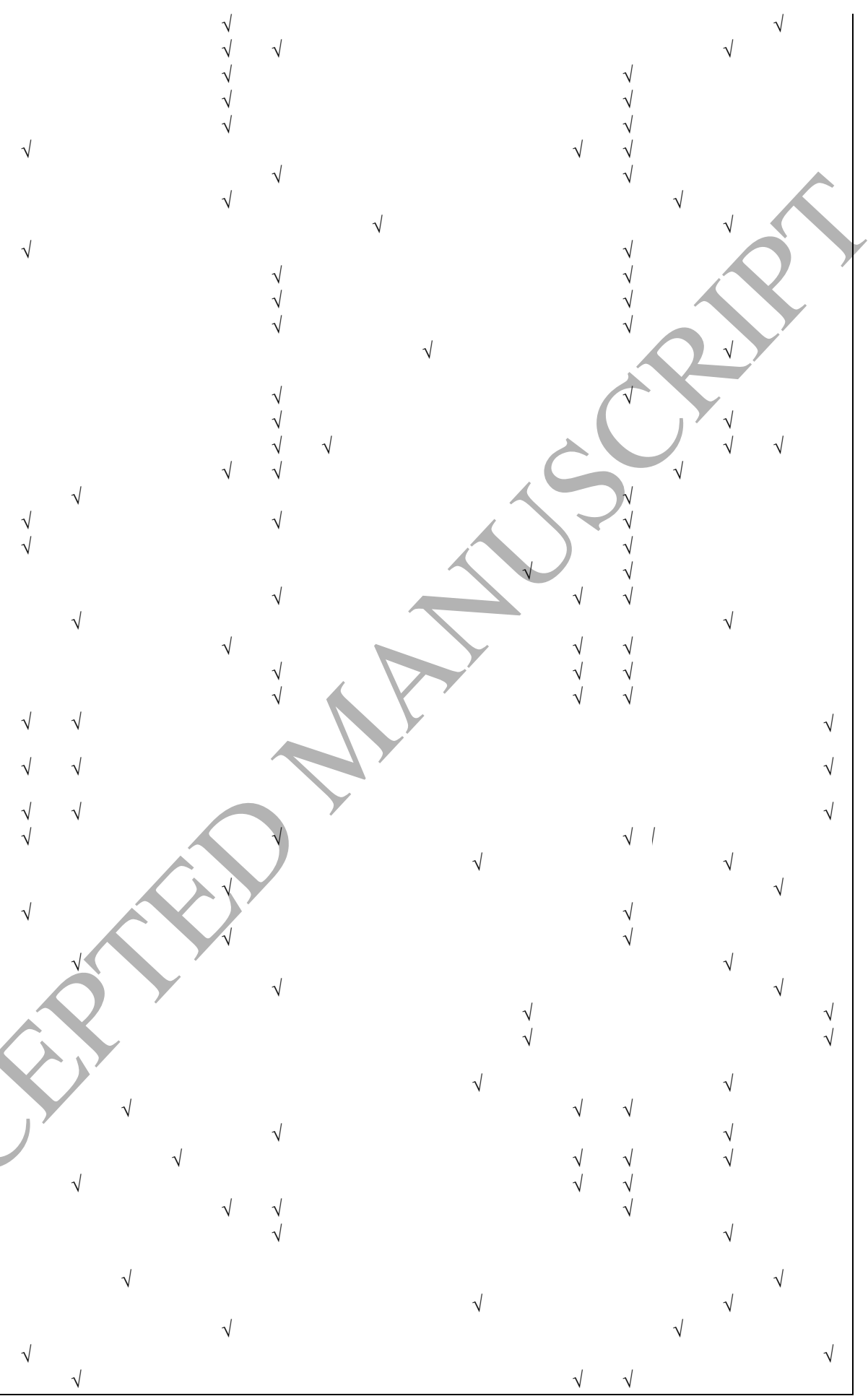




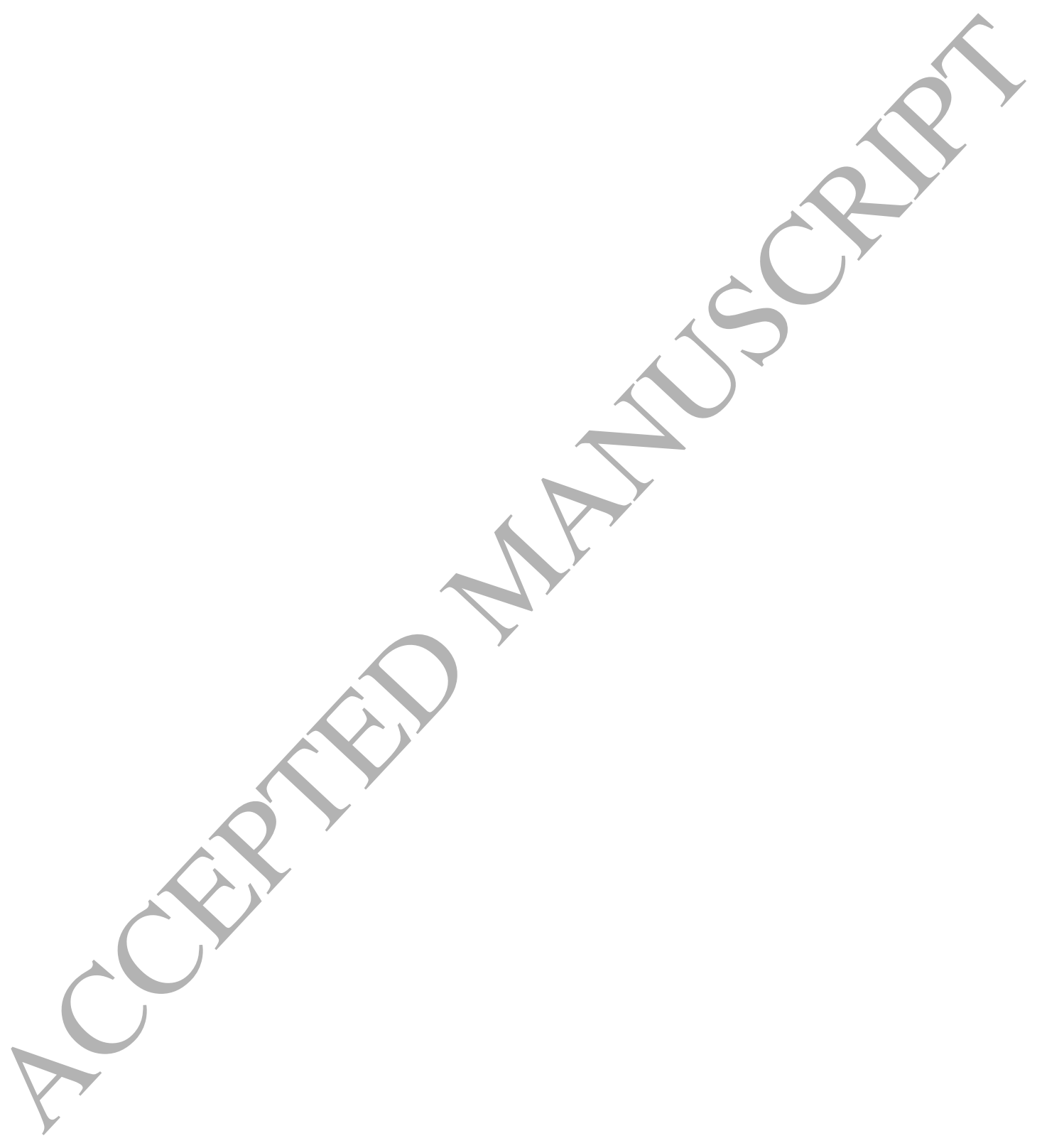

